\title{
Methylenedioxyamphetamine (MDA) and Methylenedioxymetham- phetamine (MDMA) Cause Selective Ablation of Serotonergic Axon Terminals in Forebrain: Immunocytochemical Evidence for Neurotoxicity
}

\author{
E. O'Hearn, ${ }^{\text {a }}$ G. Battaglia, ${ }^{1,}{ }^{1,}$ E. B. De Souza, ${ }^{1}$ M. J. Kuhar, ${ }^{1}$ and M. E. Molliver
}

Departments of Neuroscience, and Neurology, The Johns Hopkins University School of Medicine, Baltimore, Maryland 21205, and 'Neuroscience Branch, Addiction Research Center, National Institute on Drug Abuse, Baltimore, Maryland 21224

The psychotropic amphetamine derivatives 3,4-methylenedioxyamphetamine (MDA) and 3,4-methylenedioxymethamphetamine (MDMA) have been used for recreational and therapeutic purposes in man. In rats, these drugs cause large reductions in brain levels of serotonin (5-HT). This study employs immunocytochemistry to characterize the neurotoxic effects of these compounds upon monoaminergic neurons in the rat brain. Two weeks after systemic administration of MDA or MDMA (20 mg/kg, s.c., twice daily for $4 \mathrm{~d}$ ), there is profound loss of serotonergic (5-HT) axons throughout the forebrain; catecholamine axons are completely spared. Regional differences in drug toxicity are exemplified by partial sparing of 5-HT axons in hippocampus, lateral hypothalamus, basal forebrain, and in some areas of neocortex. The terminals of 5-HT axons are selectively ablated, while axons of passage and raphe cell bodies are spared. Thickened preterminal fibers exhibit increased staining due to damming-up of neurotransmitter and other axonal constituents. Fine 5-HT axon terminals are extremely vulnerable to these drugs, whereas terminal-like axons with large varicosities survive, raising the possibility that some 5-HT axons may be resistant to the neurotoxic effects. At short survivals, visualization of greatly swollen, fragmented 5-HT axons provides anatomic evidence for degeneration of 5-HT projections. The results establish that MDA and MDMA produce structural damage to $5-\mathrm{HT}$ axon terminals followed by lasting denervation of the forebrain. Both drugs have similar effects, but MDA produces a greater reduction of 5-HT axons than does MDMA at the same dosage. The selective degeneration of 5-HT axons indicates that these drugs may serve as experimental tools to analyze the organization and function of 5-HT projections. Caution should be exercised until further studies determine whether these compounds may be hazardous in man.

\footnotetext{
Received May 29, 1987; revised Dec. 17, 1987; accepted Dec. 21, 1987.

This work was supported by NIH, USPHS Grants NS-15199, NS-21011, and DA-04431. We are deeply grateful to Patrice Carr for technical assistance and Patricia O'Neill for secretarial help.

Correspondence should be addressed to Mark E. Molliver, M.D., Department of Neuroscience, The Johns Hopkins University School of Medicine, $725 \mathrm{~N}$. Wolfe Street, Baltimore, MD 21205.

${ }^{a}$ Present address: Department of Internal Medicine, Yale-New Haven Hospital, 20 York Street, New Haven, CT 06504.

b Present address: Department of Pharmacology, Loyola University Medical Center, Stritch School of Medicine, 2160 S. First Avenue, Maywood, IL 60153.

Copyright (C) 1988 Society for Neuroscience $0270-6474 / 88 / 082788-16 \$ 02.00 / 0$
}

The synthetic amphetamine derivatives 3,4-methylenedioxyamphetamine (MDA) and 3,4-methylenedioxymethamphetamine (MDMA) are potent mood-altering drugs that have attained public interest (Seymour, 1986) due to their widespread, self-administration by young adults (e.g., Klcin, 1985). Thesc drugs have also been proposed for medical use in psychotherapy because they produce augmentation of mood and enhanced insight (Naranjo et al., 1967; Yensen et al., 1976; Di Leo, 1981; Greer and Tolbert, 1986; Grinspoon and Bakalar, 1986). However, concern has been raised about the safety of these compounds based on evidence that they may be toxic to brain serotonin (5-HT) neurons (Ricaurte et al., 1985).

Drug discrimination studies in the rat indicate that MDA mimics both the hallucinogenic action of 2,5-dimethoxy-4methylamphetamine (DOM) and the stimulant-like effects of cocaine and amphetamine (Glennon et al., 1982; Glennon and Young, 1984a-c). Both MDA and MDMA produce stimulant (amphetamine-like) and psychotomimetic effects in man (Thiessen and Cook, 1973; Shulgin and Nichols, 1976; Anderson et al., 1978; Shulgin, 1978), as in other experimental animals (Nozaki et al., 1977; Marquardt et al., 1978). The subjective effects of MDA and MDMA in humans are similar; both drugs induce an altered state of consciousness which includes an increased sense of well-being, heightened capacity for insight, and emotional closeness to others (Braun et al., 1980; Downing, 1986; Greer and Tolbert, 1986; Grinspoon and Bakalar, 1986; Siegel, 1986). MDMA reportedly has a calming effect and rarely produces the visual imagery and hallucinations of LSD (Naranjo et al., 1967; Braun et al., 1980).

Hallucinogenic drug effects are thought to be mediated primarily through 5-HT neurons in the CNS. The prototypic hallucinogen, LSD, decreases turnover of 5-HT in the rat brain (Freedman, 1961) due largely to inhibition of 5-HT neurons in the dorsal raphe nucleus (Aghajanian et al., 1968). In contrast, phenylisopropylamine hallucinogens like DOM have little direct effect on raphe cell bodies (Aghajanian et al., 1970). Radioligand binding studies indicate that these compounds have higher affinity at $5-\mathrm{HT}_{2}$ versus $5-\mathrm{HT}_{1}$ receptors (Shannon et al., 1984) and that potency of these drugs correlates with their affinity for $5-\mathrm{HT}_{2}$ receptors (Glennon et al., 1984). The hypothesis that some of these drugs act at $5-\mathrm{HT}_{2}$ receptors (Glennon, 1985) is supported by evidence that the behavioral effects are blocked by ketanserin, a 5- $\mathrm{HT}_{2}$ antagonist (Heym et al., 1984).

Recent studics show that MDA and MDMA produce decreases in neurochemical markers for $5-\mathrm{HT}$ in the forebrain. 
Ricaurte et al. (1985) reported that MDA causes a lasting reduction in levels of 5-HT and 5-HIAA, and in 5-HT uptake with no effect on catecholamines. A similar biochemical effect has been reported for MDMA (Schmidt et al., 1986), and MDA produced a greater decrease in serotonergic markers than did MDMA (Stone et al., 1986). The lasting decreases in 5-HT markers suggest that both drugs cause degeneration of 5-HT neurons (Ricaurte et al., 1985; Schmidt et al., 1986). Following administration of MDA, axon degeneration was seen in the striatum (Ricaurte et al., 1985) using the Fink-Heimer method, a silver stain for degenerating axons. This histologic finding, along with decreased chemical markers for 5-HT, suggests that MDA has a neurotoxic effect on 5-HT axons, but silver methods do not provide identification of the neurotransmitter utilized by degenerating fibers. Moreover, this staining method has low sensitivity for NE or 5-HT axons since it does not detect cortical axon degeneration after lesions of the medial forebrain bundle (MFB) (Moore and Heller, 1967). The silver methods at best stain a small fraction of the degenerating 5-HT axons in cerebral cortex following raphe lesions (Hedreen, 1973).

In order to assess the cytotoxic effects of MDA and MDMA in the rat brain, we employed immunocytochemistry for the visualization of 5-HT and catecholamine neurons. This approach has made it feasible to obtain structural evidence for axon degeneration, to identify specific neurons and neuronal compartments that are damaged by neurotoxic drugs, and to determine the regional distribution of the effect. The results of this study should help to define the sites of drug action and the neural mechanisms that underlie psychedelic drug effects and neurotoxicity.

\section{Materials and Methods}

Adult male Sprague-Dawley rats weighing 150-220 gm (Harlan Industries, Walkersville, MD) received 8 doses of $( \pm$ MDA $(n=5)$, $( \pm$ MDMA $(n=5)$, or equal volumes of $0.9 \% \mathrm{NaCl}(n=5)$ injected subcutaneously (s.c.) every $12 \mathrm{hr}$ for $4 \mathrm{~d}$ and were sacrificed 2 weeks after the last dose. Each dose was equivalent to $20 \mathrm{mg} / \mathrm{kg}$ of the free base. To study subacute drug effects, additional rats $(n=6)$ received the same dose of MDA s.c. every $12 \mathrm{hr}$ for $2 \mathrm{~d}$ and were sacrificed 1 or $3 \mathrm{~d}$ after the fourth injection. Animals were housed 3-5 per cage at $70^{\circ} \mathrm{F}$ with a $12 \mathrm{hr}$ light-dark cycle and given free access to food and water. Typical behavioral effects were observed for $3-4 \mathrm{hr}$ following drug administration. Treated rats remained close to the ground and displayed forepaw treading, arched tail, repetitive, stereotyped grooming, and wet fur. All of the animals survived the course of drug treatment.

At survival times of 1,3 , or $14 \mathrm{~d}$, rats were given $10 \mathrm{mg} / \mathrm{kg}$ i.p. of the monoamine oxidase inhibitor trans-2-phenylcyclopropylamine $\mathrm{HCl}$ (Regis Chemical Co., Morton Grove, IL). Two hours later the rats were deeply anesthetized with chloral hydrate $(400 \mathrm{mg} / \mathrm{kg}$ i.p.) and fixed by intracardiac perfusion. The vasculature was cleared with PBS (pH 7.4, $4^{\circ} \mathrm{C}$ ) and then perfused with fixative containing $4 \%$ paraformaldehyde (PAF) and $0.1 \%$ glutaraldehyde in $500 \mathrm{ml}$ of $0.15 \mathrm{M}$ phosphate buffer $\left(\mathrm{pH} 7.4,4^{\circ} \mathrm{C}\right.$ ) delivered by peristaltic pump at $50 \mathrm{ml} / \mathrm{min}$. The brains were then immersed 4-6 hr in $0.15 \mathrm{M}$ phosphate buffer with $4 \% \mathrm{PAF}$ and cryoprotected in $10 \%$ dimethylsulfoxide in PBS ( $3 \mathrm{hr}$ ). Frozen blocks were sectioned at $30 \mu \mathrm{m}$ on a sliding microtome. Sagittal sections of the cerebral hemisphere were obtained $1.5-3.0 \mathrm{~mm}$ lateral to the midline; transverse sections of the midbrain were collected to examine the raphe nuclei.

Sections were incubated $\left(20 \mathrm{hr}, 4^{\circ} \mathrm{C}\right)$ in rabbit antisera directed against protein-bound 5-HT (prepared by Dr. H. G. W. Lidov) diluted 1:6000 or against tyrosine hydroxylase (TH) (Eugene Tech) diluted 1:4000 in PBS, both containing $1 \%$ normal goat serum and $0.2-0.3 \%$ Triton. The properties of the 5-HT antiserum have been described previously (Steinbusch et al., 1978; Lidov et al., 1980). Sections were processed by the avidin-biotin-peroxidase complex (ABC) method of Hsu et al. (1981) (Vector Laboratories, Burlingame, $\mathrm{CA}$ ). The peroxidase label is visu- alized by exposing the sections to diaminobenzidine tetrahydrochloride and enhanced with osmium and thiocarbohydrazide (Electron Microscopy Sciences, Fort Washington, PA), an osmiophilic reagent (Gerfen, 1985). The sections were coverslipped with Histoclad and examined by bright-and dark-field microscopy. Adjacent frozen sections were stained by the Nissl method with cresyl violet.

\section{Results}

Gross changes in 5-HT-immunoreactive staining

In animals treated with MDA or MDMA, sections prepared for 5-HT immunocytochemistry are faintly stained and extremely pale compared with control sections, which have a deep tan color. The pale staining, evident with the naked eye, reflects a marked reduction in the density of 5-HT axons throughout most parts of the forebrain. Regional differences in staining intensity indicate that neocortex, striatum, and thalamus sustain the greatest loss of 5-HT innervation. A smaller reduction in 5-HT staining is seen in the hippocampal formation, septum, olfactory bulb, and amygdala. Serotonergic staining appears relatively spared in the hypothalamus and midbrain, while immunoreactivity in the basal forebrain of treated animals is increased over that in controls. In contrast, catecholamine innervation appears to be unaffected by these drugs since sections prepared for THI immunoreactivity reveal no differences between control and treated animals.

\section{Cerebral cortex}

Regional differences in denervation. Dorsal neocortex from the frontal to the occipital pole was studied in parasagittal sections obtained $2-3 \mathrm{~mm}$ lateral to the midline. Normal rats display regional differences in the pattern of 5-HT innervation of cerebral cortex: axon density is maximum at the frontal pole and decreases posteriorly. Frontal (motor) cortex contains a particularly dense, highly arborized plexus of 5-HT axons (Fig. 1). An abrupt decrease in axon density is seen at the border of motor (AGl) and somatosensory cortex in controls, and there is a further, but smaller decrease in occipital cortex. In most areas, 5-HT axons extend across the full thickness of cortex, as described previously (Lidov et al., 1980).

Following the administration of MDA or MDMA, there is a marked reduction in the density of 5-HT axons in all regions and across all layers of neocortex. A comparable pattern of denervation is observed at each survival time examined ( $1 \mathrm{~d}-$ 2 weeks). Although the denervation of cerebral cortex is severe, some 5-HT axons survive; the number of remaining fibers differs in each region. Within neocortex, spared axons are most numerous at the frontal pole, and there is a gradient of decreasing density from frontal to occipital cortex. Dorsal frontal cortex (AGl) contains a modest number of spared 5-HT axons that are distributed uniformly across all layers (Fig. 1). In parietal cortex (Fig. 2), the density of 5-HT axons remaining after drug treatment is far less than in frontal cortex, and there is a further small reduction in occipital cortex (Fig. 3). When treated animals are compared with controls, the numbers of 5-HT axons remaining in different arcas of ncocortex appcar to be roughly proportional to the normal innervation density.

Effects of MDMA versus MDA. MDMA and MDA both produce a similar pattern of 5-HT denervation in cerebral cortex and in other parts of the brain. The regional distribution of denervation is the same for both compounds. When the effects are compared at the same dosage, there is a smaller reduction in 5-HT innervation density following MDMA than after MDA (Figs. 1-3). 


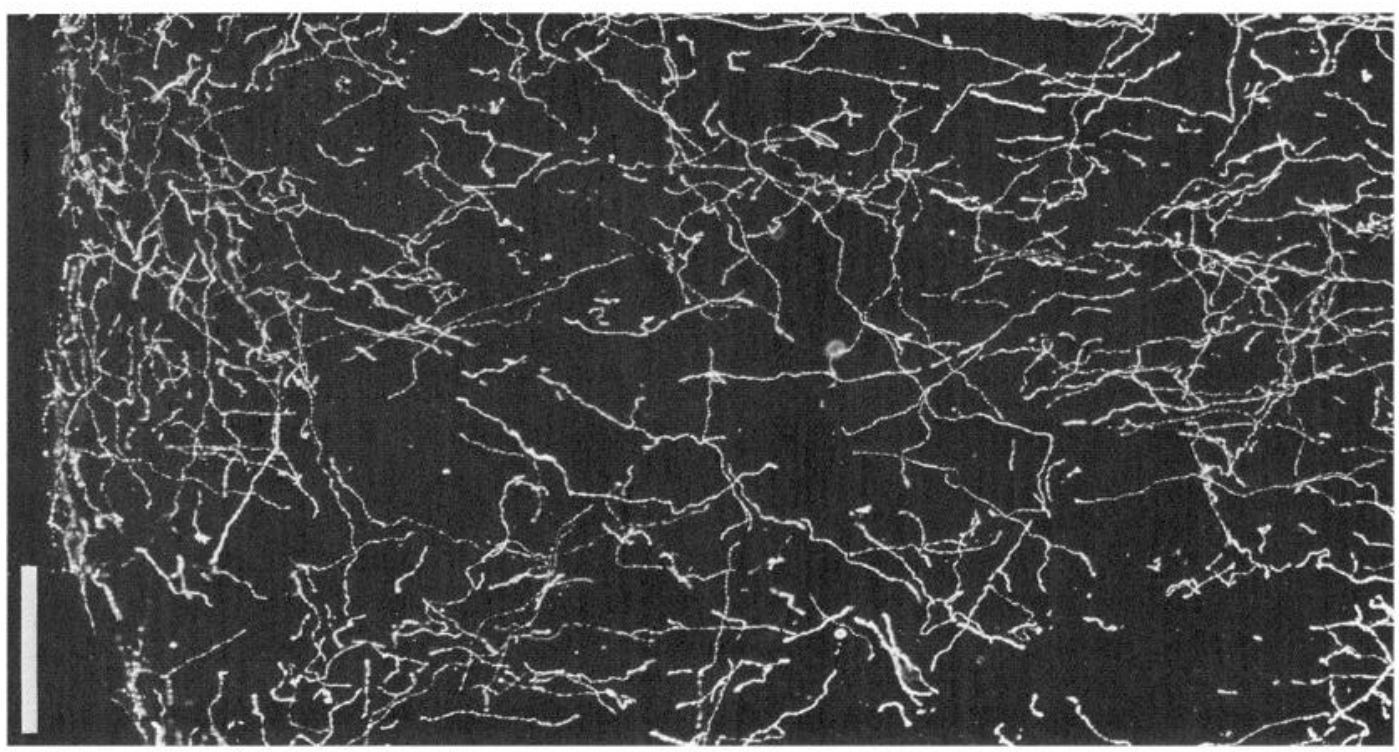

a

工象造 氖家

政

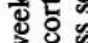

त出

它范

.

雪.

a

急急

然

定学.

窟

要.

동ำ

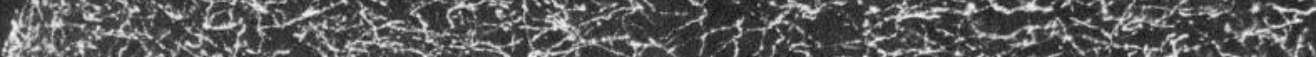

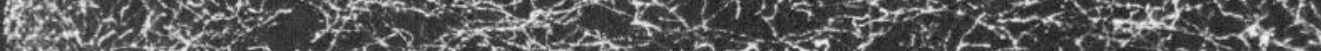

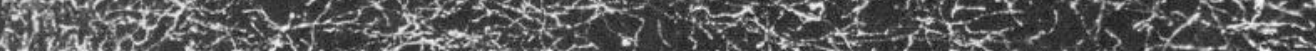

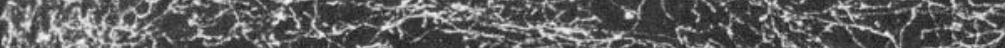

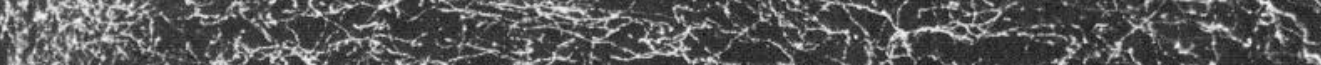

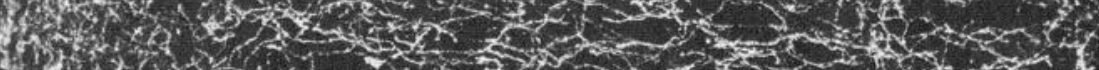

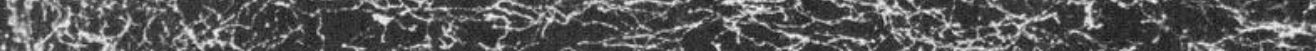

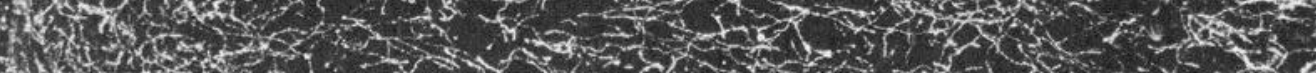

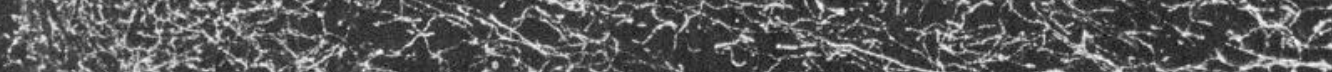

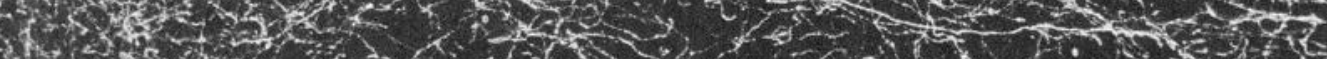

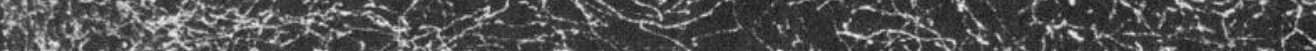

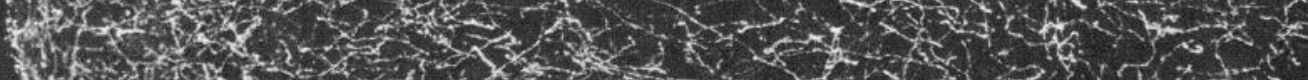

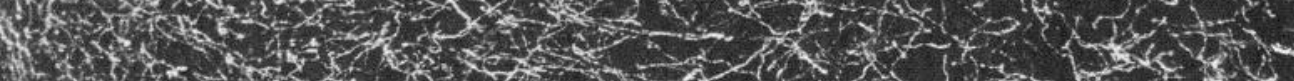

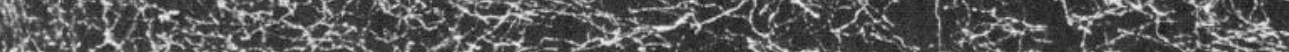

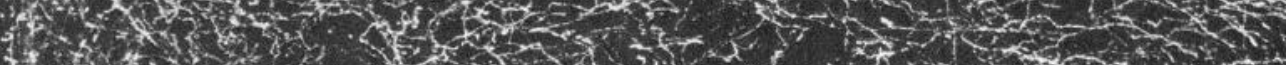
3 3.

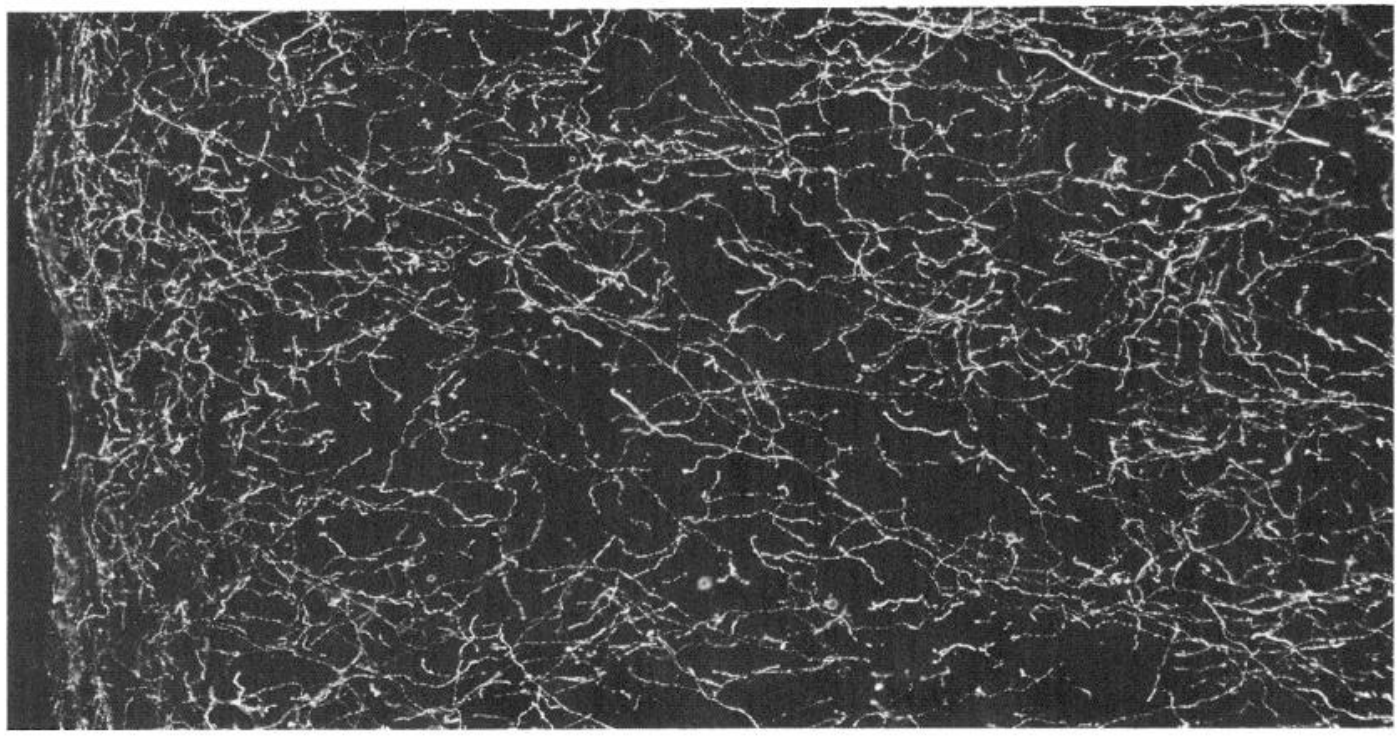

○

논

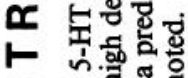

2 a.

0 跑

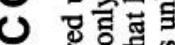

응

응

口. 임

촌 정

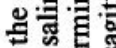

드웡

仓ิ

ष串和

돈

은

8 .

응. 젼

总空里

×ல

동

현뎡

$\sum$

5.

\$

ด

敋

형 영

盟

현롱.

ڤ

홍응

충

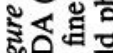

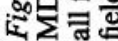



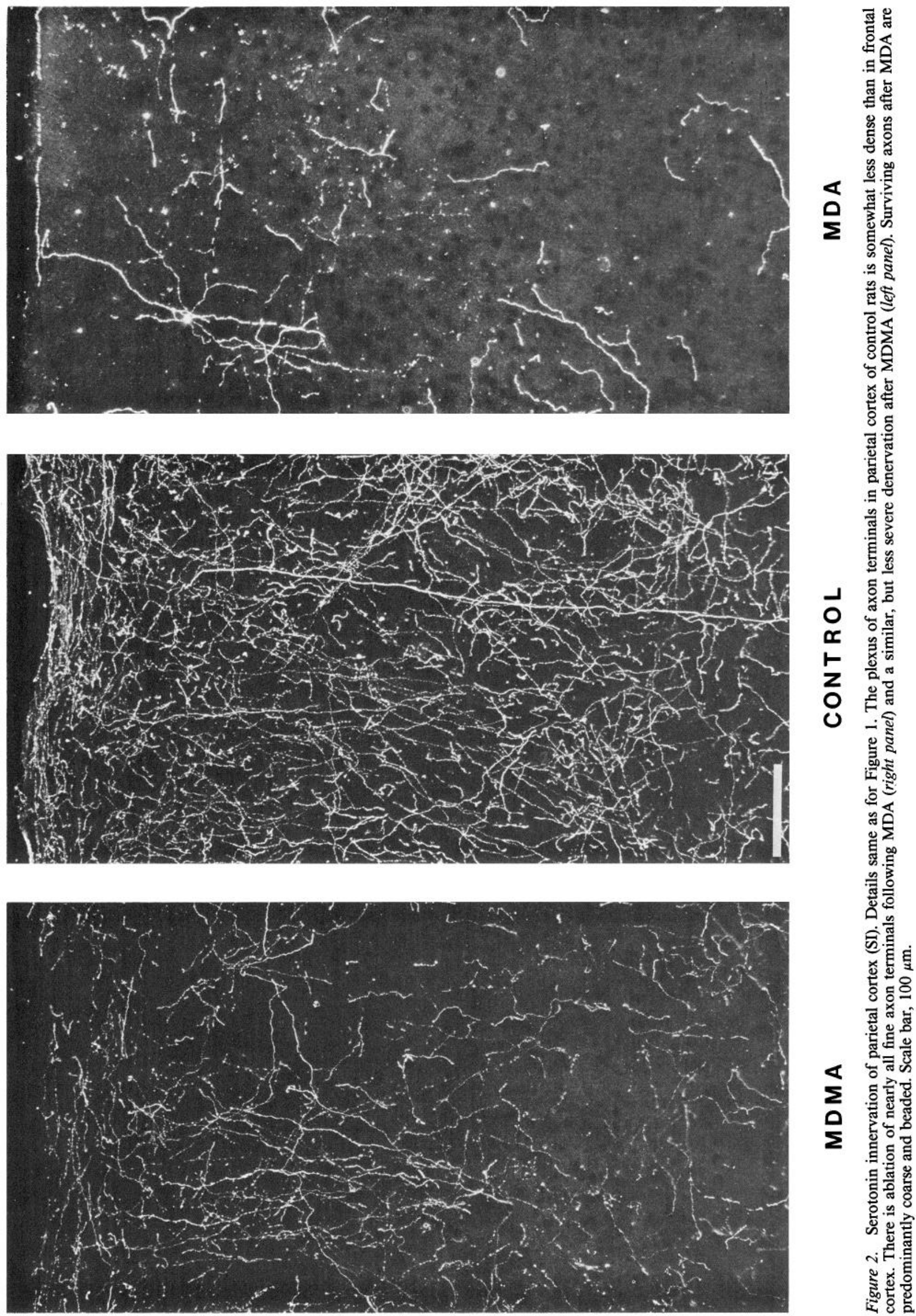

.

통

웅응

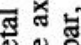

둥ㅇ

क तै

둥를

政

둥

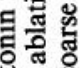

은

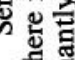

iF

密它宽 


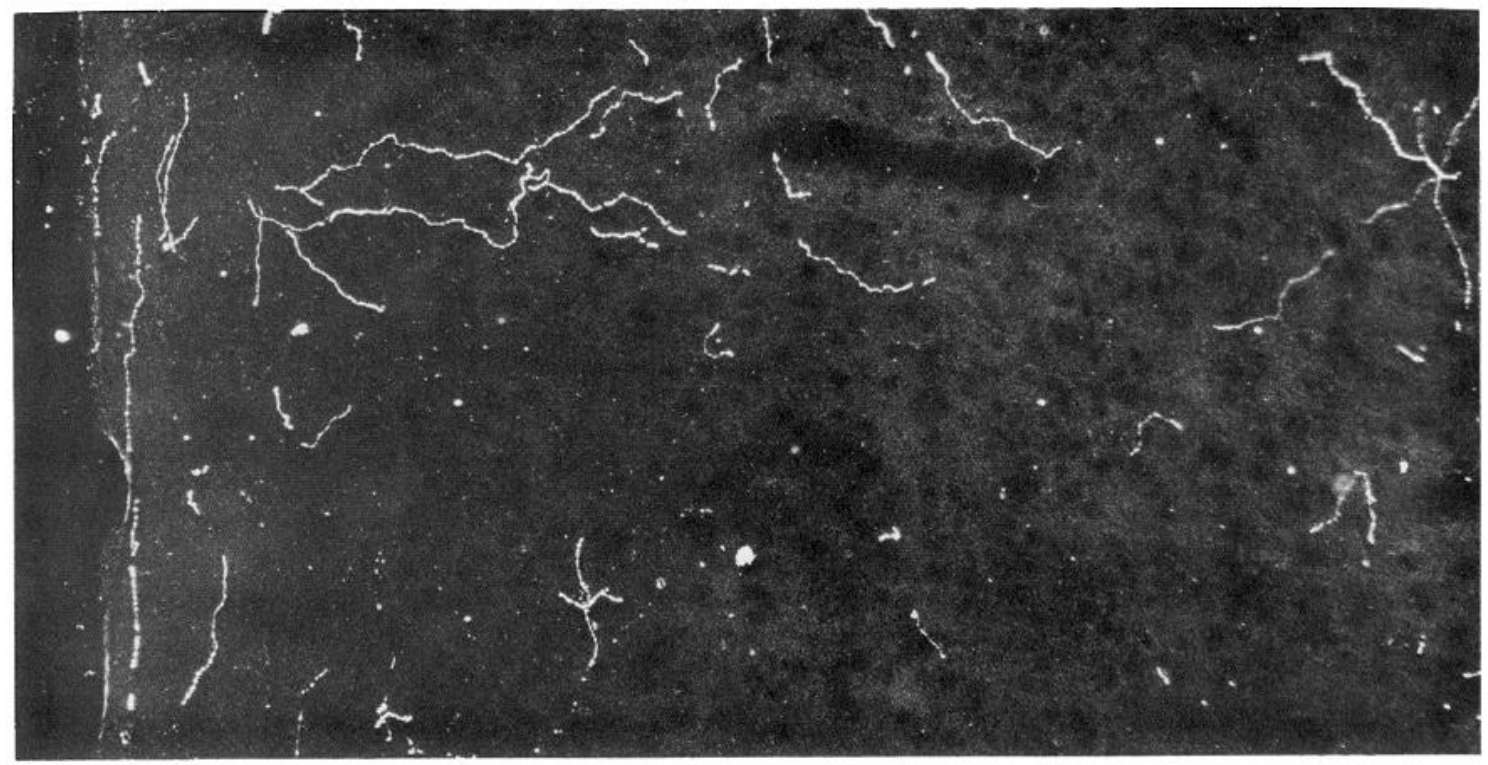

늘
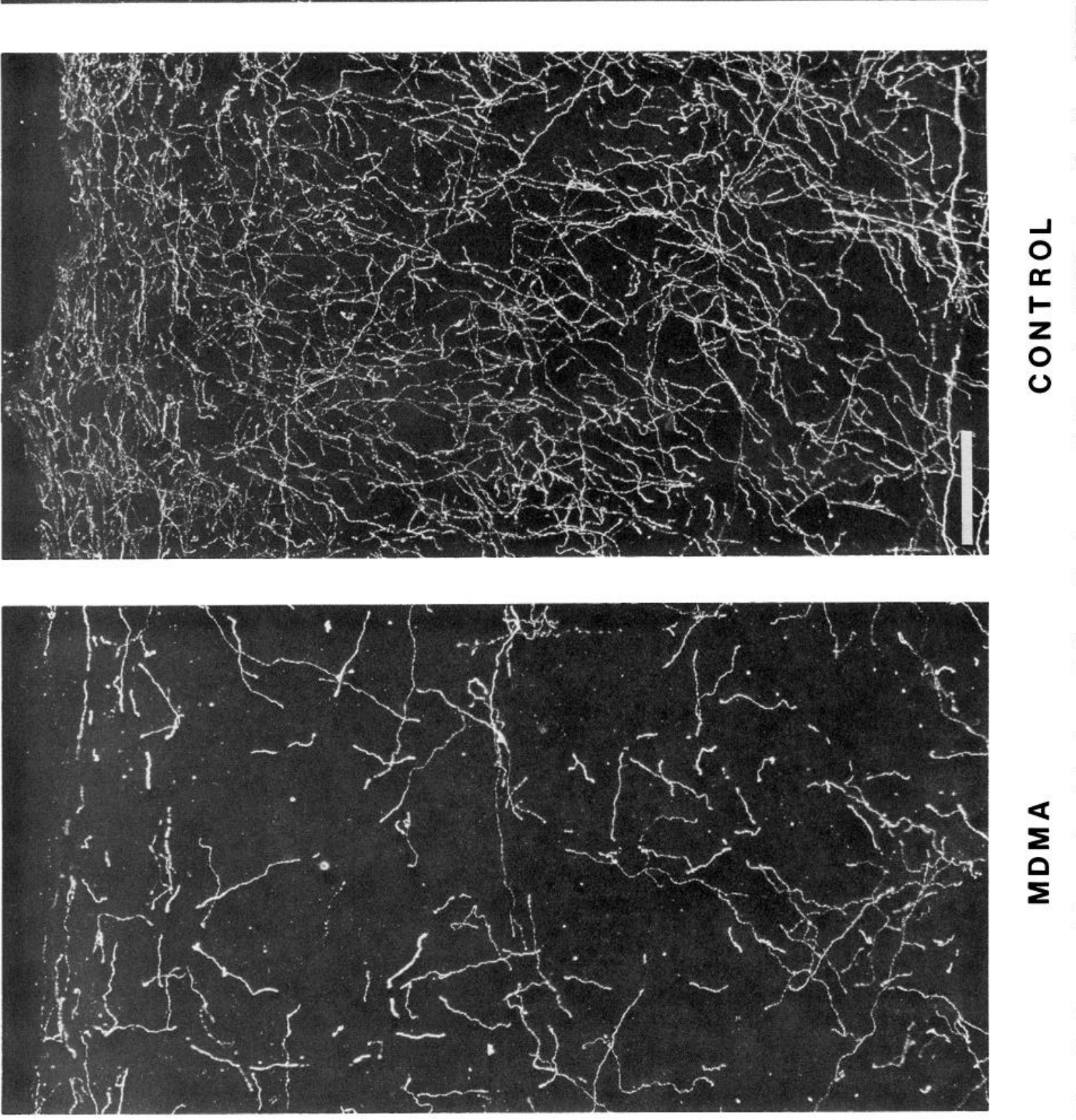
Axon morphology and vulnerability. Not only is the density of 5-HT axons markedly diminished at 2 week survivals, but the proportion of different 5-HT axon types differs from that in controls. In normal animals, the most abundant 5-HT axons found in all areas of cortex are fine, arborized terminals with small fusiform varicosities. Thicker fibers with a radial orientation are interspersed with these highly branched, fine axons; the thick, radial fibers appear to be preterminal axons. Following MDA administration, the number of fine, terminal-like axons is markedly reduced in all cortical areas; MDMA-treated animals show a smaller reduction in axon density and some fine axons remain. In parietal cortex, the dense plexus of fine terminals seen in layer $\mathrm{V}$ of controls is completely ablated by MDA. Most of the 5-HT axons remaining in frontal cortex 2 weeks after drug treatment are considerably thicker than in controls and are more intensely immunoreactive than normal. Spared fibers of this type are presumably preterminal axons; they are particularly evident in the middle layers of frontal cortex (Fig. 4). In both frontal and parietal cortex, many smooth, straight, tangentially oriented 5-HT fibers extend longitudinally through layer VI just over the corpus callosum (Fig. 5). These presumptive axons of passage appear not to be reduced in number but are thickened and more intensely stained following MDA.

In some areas of cortex, there remains a small number of 5-HT fibers that differ morphologically from the preterminal axons described above. These spared axons have large spherical varicosities. Following MDA, scattered clusters of these densely stained, beaded axons are found in cortical layers I-III, especially in the posterior half of the hemisphere. While it is difficult to establish that these beaded axons are not abnormal forms, axons with similar morphology are found in cortex of control animals, where they constitute a minority of 5-HT terminals.

\section{Short survival-degeneration}

In an effort to identify active degeneration of axons, sections were examined at short survival times after drug treatment. One to three days after 4 doses of MDA, numerous morphologically abnormal 5-HT fibers are seen in the cerebral cortex. The frequency and severity of these cytologically abnormal axons are much greater at 1 and $3 \mathrm{~d}$ than at 2 weeks after drug administration. Serotonin-positive axons display features of acute degeneration, such as enormous, swollen varicosities, irregularly thickened intervaricose segments, and intense 5-HT immunoreactivity. Grossly abnormal 5-HT elements in cortex were more frequent after 1 d survivals (4-5/microscope field with $40 \times$ objective) than after 3 d survivals (1-2/40 $\times$ field). At 2 week survivals, degenerating axonal forms were rarely observed.

Numerous greatly swollen varicosities are seen in all cortical areas (Fig. 6). The most frequent abnormalities consist of markedly dilated axons with irregular diameter, giant varicosities and fragmentation of axon segments. These abnormal dilatations were never observed in controls and are at least 4 times the diameter of the largest 5-HT axonal varicosities seen in the normal brain. The giant varicosities appear to be newly formed structural abnormalities and differ in regional distribution from normal axons that have large, round varicosities. The giant varicose swellings are most numerous in frontal cortex and decrease in frequency posteriorly, in parietal and occipital areas. In control animals, frontal cortex has the highest 5-HT innervation density and contains few 5-HT axons with large varicosities. Accordingly, the incidence of giant varicosities follow-

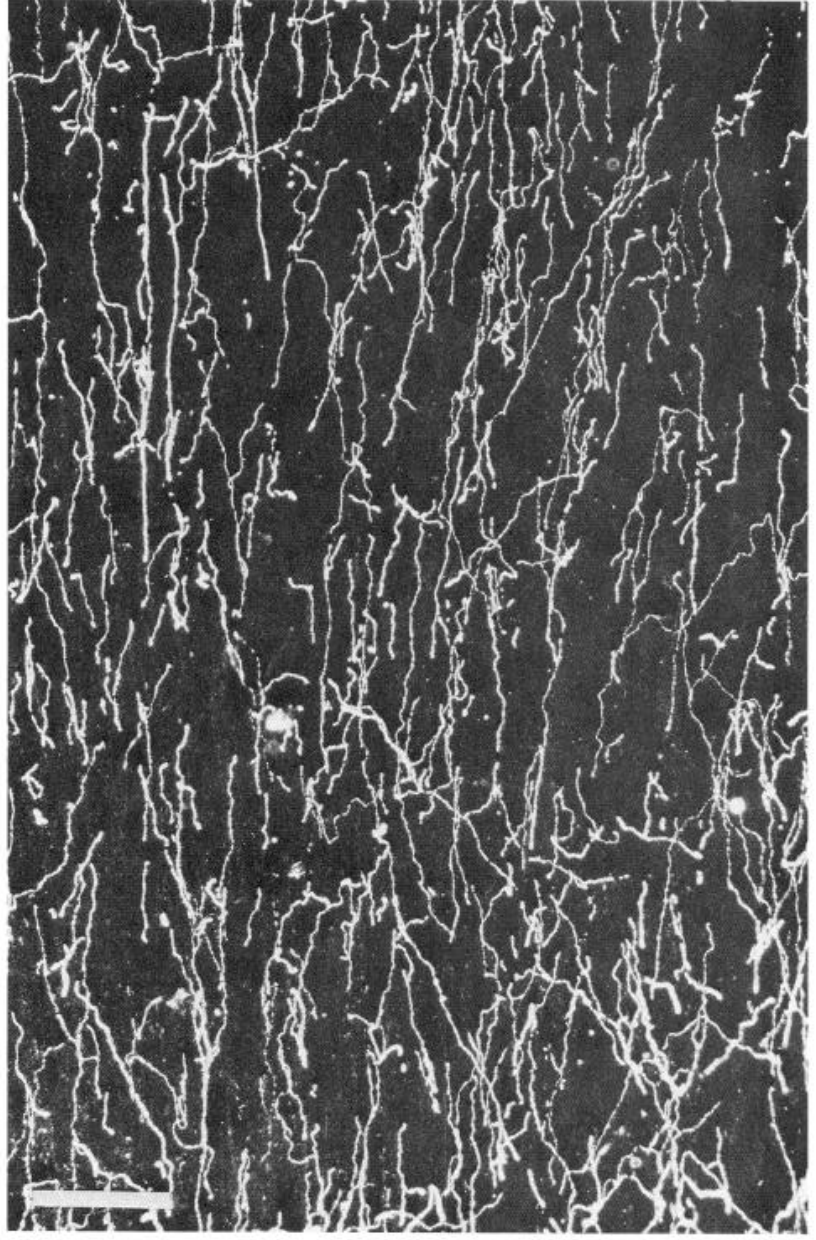

Figure 4. Thickened 5-HT axons in frontal cortex following MDA. This micrograph from the middle layers of frontal cortex demonstrates the sparing of large-diameter, intensely immunoreactive preterminal fibers, which have a radial orientation. The fine axon terminals that normally populate this region have been almost totally ablated. Survival time is 2 weeks after 8 doses of $20 \mathrm{mg} / \mathrm{kg}$. Scale bar, $100 \mu \mathrm{m}$.

ing drug treatment corresponds to the normal 5-HT innervation density and not to the distribution of varicose axons.

\section{Striatum}

In the normal rat both striatum and globus pallidus are densely innervated by 5-HT axons. The 5-HT innervation of both structures is markedly reduced by treatment with MDA and MDMA both at long and short survival times. The normal 5-HT innervation of the striatum consists of uniformly fine, arborizing axon terminals; a small number of smooth, straight axons of passage are present in the white matter bundles. The innervation is more dense in ventral than in dorsal striatum. In the globus pallidus, the 5-HT innervation is more dense, and fine axons are intermixed with thicker, varicose fibers. Two weeks following MDA, there is marked denervation of 5-HT axon terminals throughout the striatum (Fig. 7). Almost no 5-HT axons can be found in the dorsal portion of the striatum; a moderate number of 5-HT axons remain ventrally, especially in the most ventral portion, the fundus striatum, where the 5-HT innervation is normally denser. Throughout the striatum nearly all of the fine arborized fibers are gone; the few remaining fibers are primarily preterminal axons. In the globus pallidus, there is also a marked 


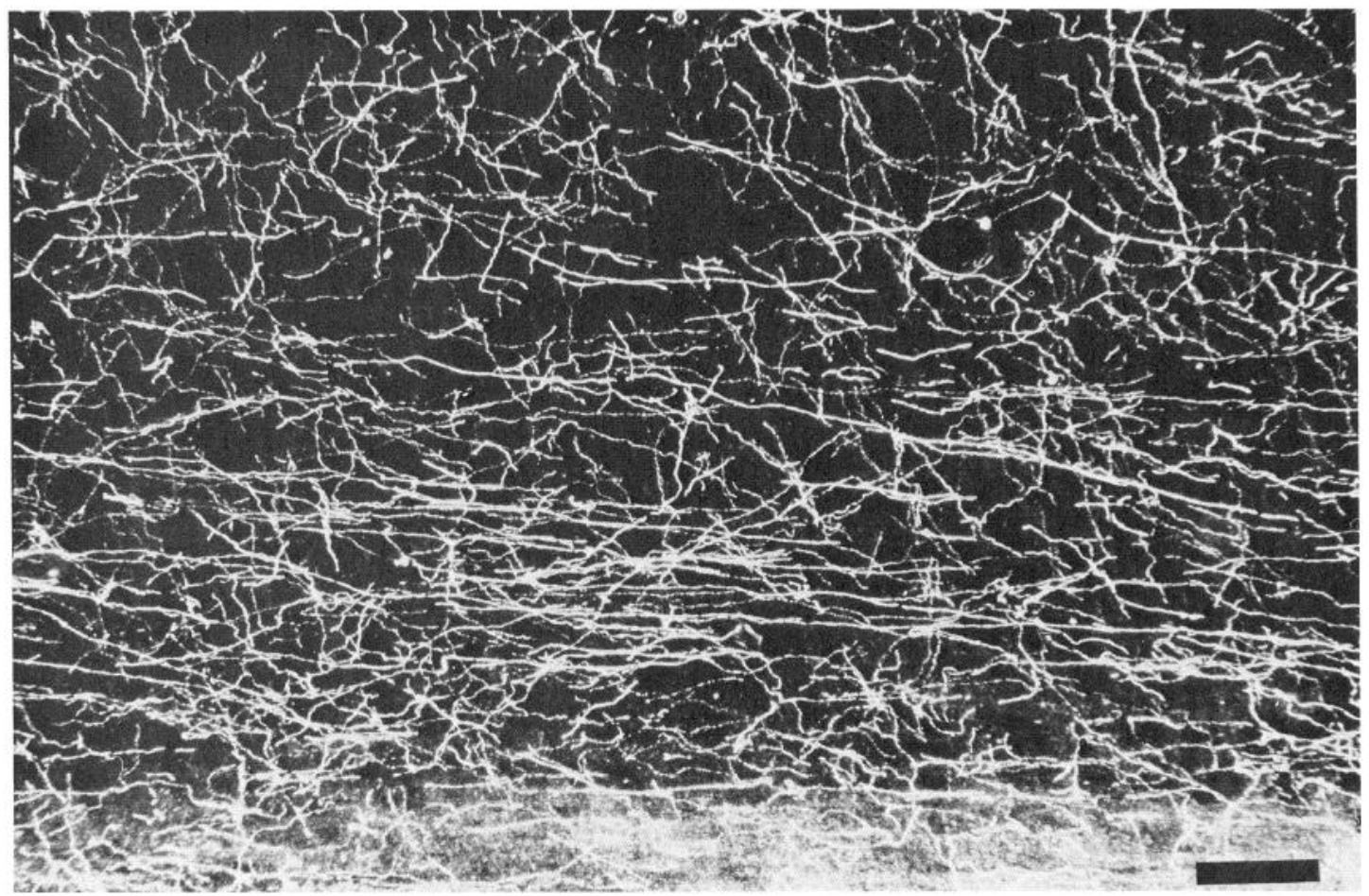

Figure 5. Serotonergic axons of passage in deep layers of parietal cortex. These longitudinal axons of passage are spared after MDA. Survival time is 2 weeks. The white matter is seen along the lower edge of the plate.

5-HT denervation, but the residual axon density is greater than in the striatum. MDMA produces a marked depletion of 5-HT axons in the striatum, but, as in neocortex, somewhat more fibers remain than after MDA.

\section{Hippocampal formation}

While the 5-HT innervation of the hippocampus is relatively spared following drug treatment, a differential pattern of axon loss and sparing is found in specific zones of the hippocampus. In control animals (Fig. 8), all zones and layers of the hippocampal formation are densely innervated by 5 - $\mathrm{HT}$ axons (Lidov et al., 1980; Kohler, 1982). In the $\mathrm{CA}_{1}$ subfield there is a particularly dense band of longitudinal, coarse axons within the stratum moleculare. There is also a dense plexus of both coarse and fine 5-HT axons in the stratum radiatum of $\mathrm{CA}_{3}$ and a band of coarse 5-HT axons in the dentate gyrus along the borders of the granule cell layer. Throughout all zones of the hippocampus, the molecular layer contains a high density of fine 5-HT axons.

MDA and MDMA administration is followed by marked ablation of 5-HT fibers in most zones of the hippocampus, but many axons are spared in certain regions. The overall density of surviving 5-HT axons in the hippocampus is much greater than in neocortex. Field $\mathrm{CA}_{1}$ exhibits the most striking denervation (Fig. 8). Most of the fine axons in $\mathrm{CA}_{1}$ disappear from all layers, yet the thick, longitudinal axons in the molecular layer persist. Many of the surviving fibers are thicker than in controls and appear to form branches extending into other layers. A dense network of coarse 5-HT axons remains along both inner and outer margins of the dentate granule cell layer and in the stratum radiatum of $\mathrm{CA}_{3}$. Serotonin axon terminals in the dentate hilus, in the molecular layer of the dentate gyrus, and in layers of $\mathrm{CA}_{1}$ other than the stratum moleculare are greatly reduced in number. The present findings demonstrate a selective, regional pattern of axon sparing in the hippocampus. As in other cortical areas, fine $5-\mathrm{HT}$ axon terminals are markedly reduced by drug treatment. Those zones in which 5-HT axons are spared after drug treatment have a high density of relatively coarse 5 -HT axons in both treated and control animals. Many of these spared fibers may be axons of passage; others may be coarse, beaded terminals. Relatively more axons are spared following MDMA than after MDA treatment, yet the regional pattern of degeneration is the same for both drugs.

\section{Other regions of the forebrain}

Other regions of the forebrain exhibit changes similar to those observed in neocortex following MDA or MDMA. The density of fine 5-HT axon terminals is markedly reduced in most areas; 5-HT axons that remain after drug treatment are stained more intensely than normal and are often thickened. The brain stem was not analyzed systematically as part of this study, yet inspection of selected sections indicates that, despite subtle changes, 5-HT innervation is relatively spared in this area as compared with forebrain.

Septum. In the septum, 5-HT axons are decreased in density

Figure 6. Acute degeneration of 5-HT axons. Serotonin axon terminals at $1 \mathrm{~d}$ survival following 4 doses of MDA. These axons exhibit cytopathologic changes consisting of enormously swollen varicosities, irregular thickening, and fragmentation of fibers. These changes are evidence of structural degeneration in 5-HT axons following treatment with MDA. Scale bar, $10 \mu \mathrm{m}$. 

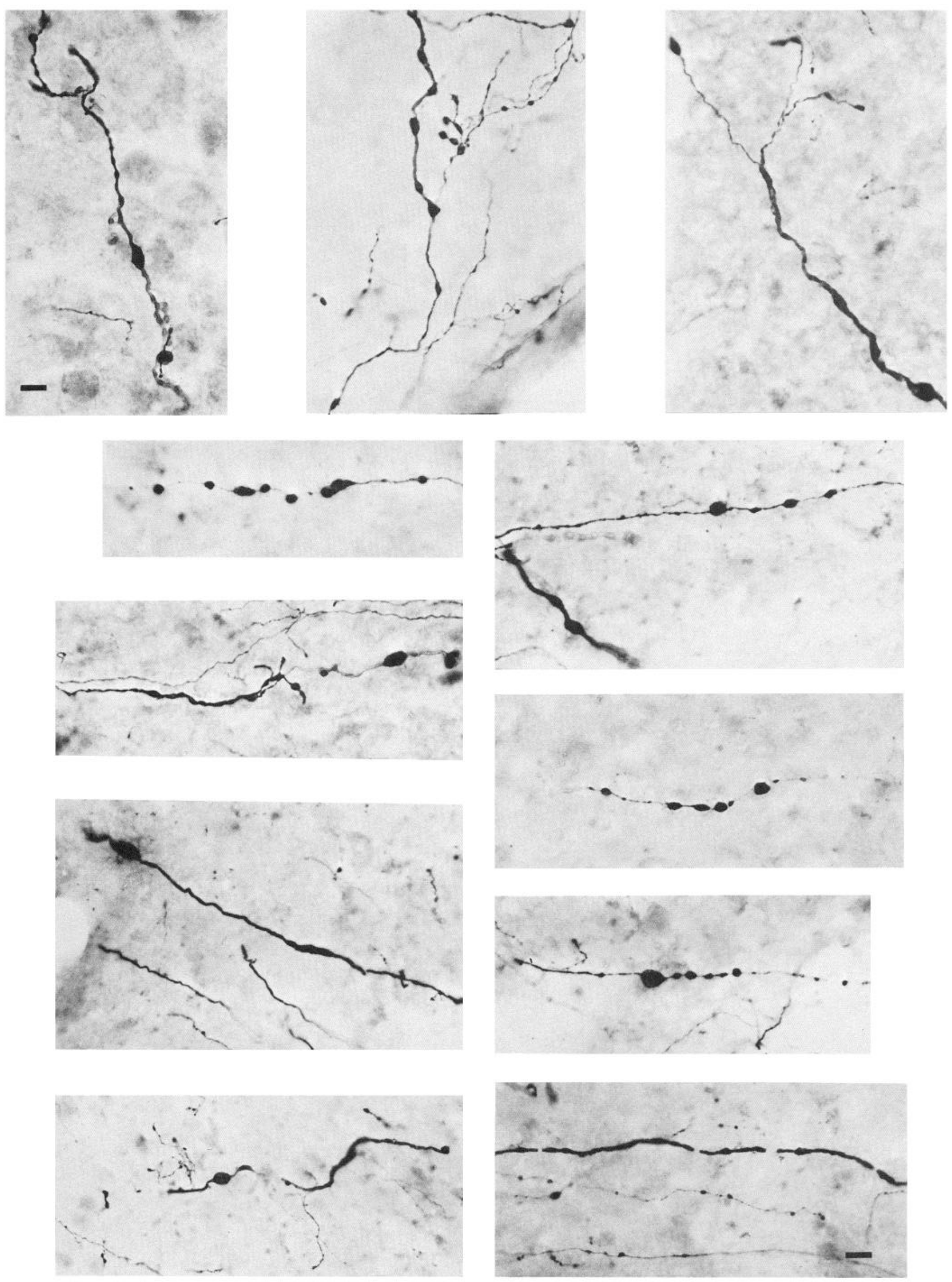

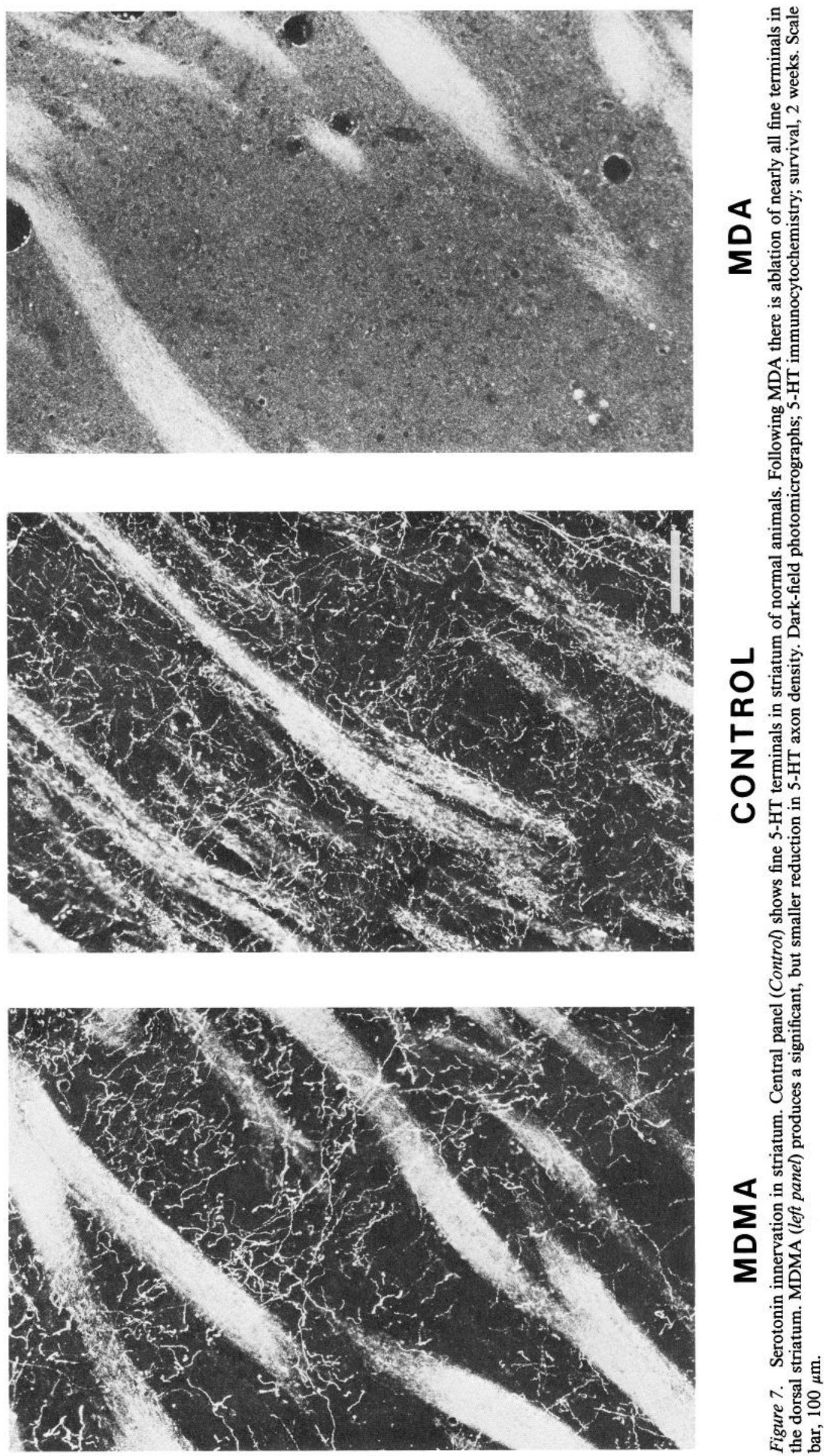

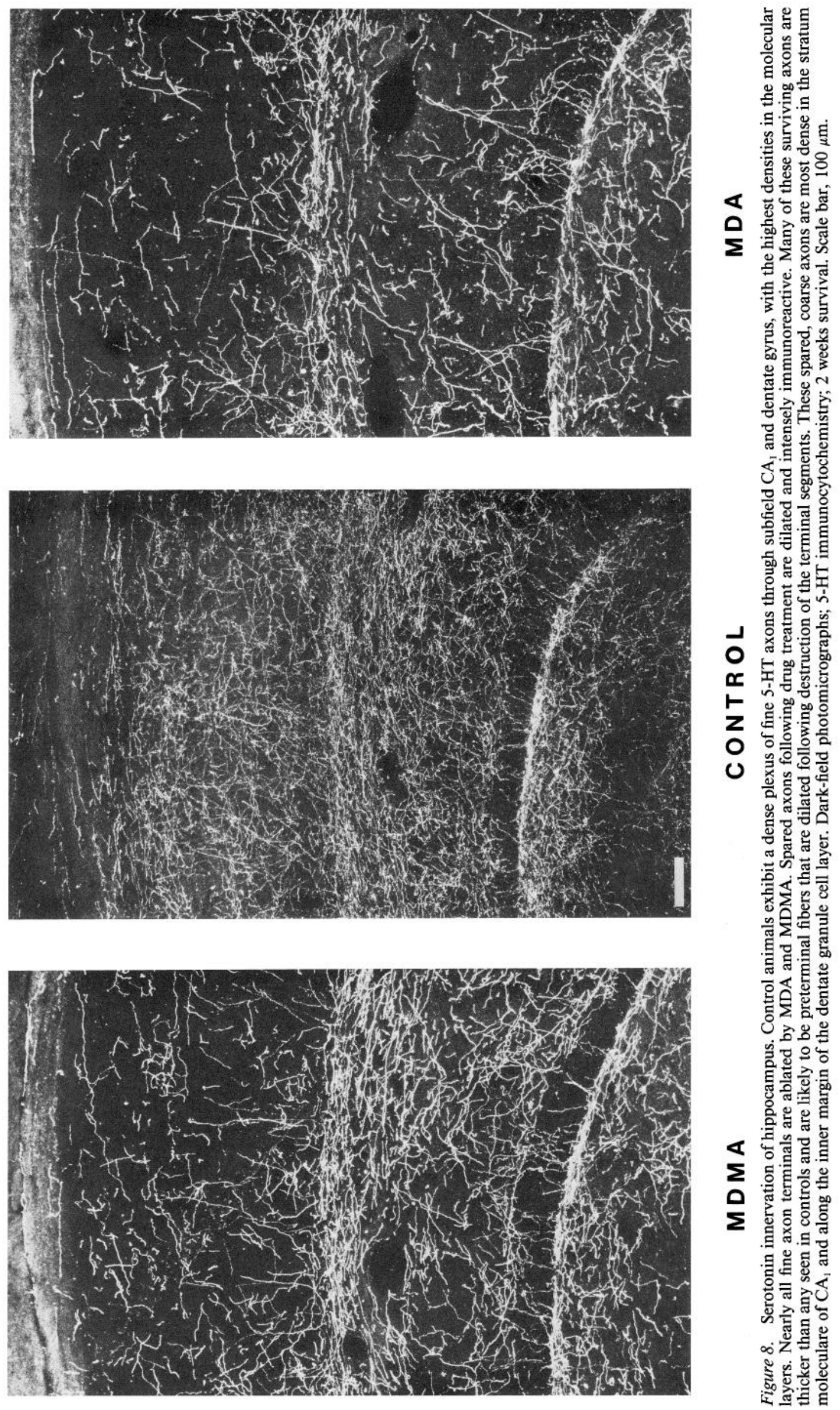


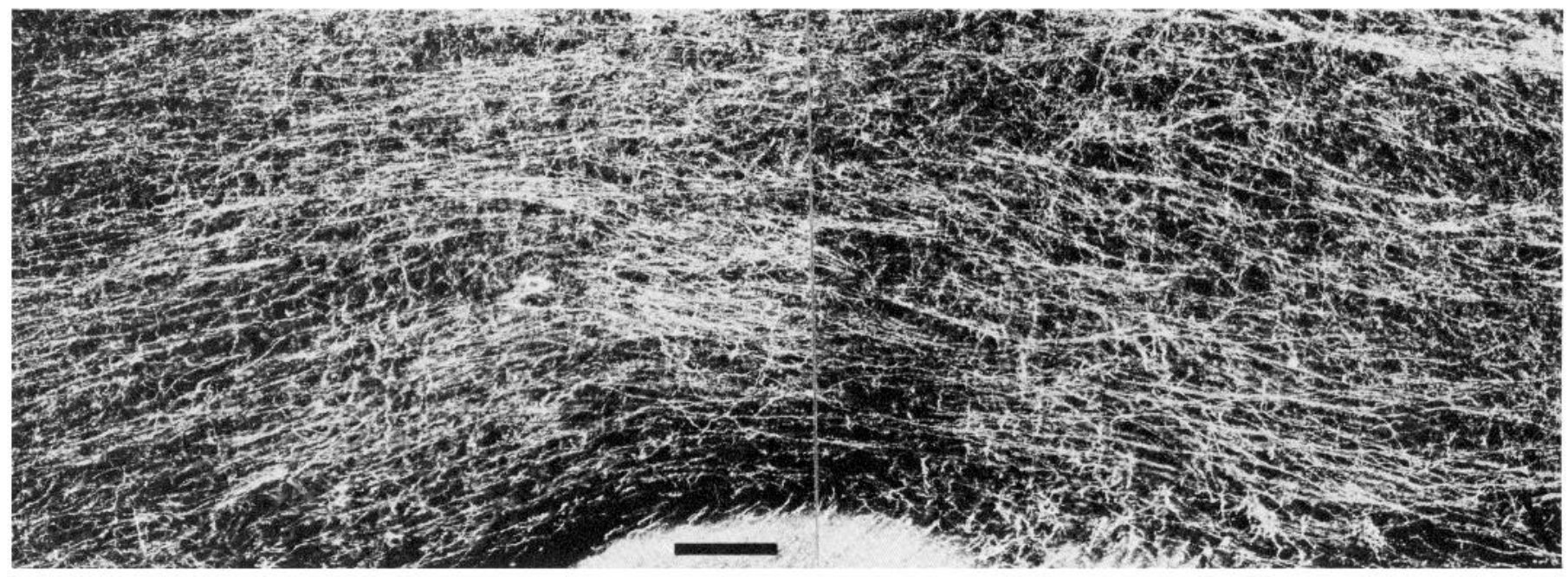

Figure 9. Serotonin axons in lateral hypothalamus following MDA. These 5-HT axons of passage which ascend here in the medial forebrain bundle are completely spared by MDA and MDMA. These axons appear somewhat more intensely stained than in controls but are not reduced in number or density. Two weeks survival. Scale bar, $100 \mu \mathrm{m}$.

after both MDA and MDMA. The residual density of 5-HT axons is far less in the lateral septal nuclei than in the medial septal nuclei. Many of the remaining 5-HT axons in the medial septum are straight, smooth fibers that appear to be axons of passage extending in a dorsal direction from the diagonal band. The 5-HT innervation of the septal nuclei is roughly proportional to their relative innervation density in control animals. Many of the axons that remain after drug treatment have increased 5-HT immunoreactivity.

Basal forebrain. This region is unique in that, at low magnification, the basal forebrain of treated animals appears more intensely stained for 5-HT than in controls. At higher magnification, drug-treated animals show regions where the density of 5-HT axon terminals is significantly reduced. This decreased density of 5-HT terminals is most evident in the olfactory tubercle, primary olfactory cortex, and the amygdaloid complex. In those regions where 5-HT staining appears more intense than normal-the ventral pallidum, the substantia innominata, and the horizontal limb of the diagonal band-the surviving 5-HT axons are longitudinally oriented and increased in thickness. The greatest density of spared 5-HT axons is within the ventral striatum, just dorsal to the olfactory tubercle and the deep olfactory radiation (Commissaris et al., 1980). This region contains ascending 5-HT fibers of passage within the medial forebrain bundle (MFB) en route to other telencephalic structures (Fig. 9). The high density of axons and intense immunoreactive

Table 1. Cell types in normal and striped tecta

\begin{tabular}{lccccccc}
\multicolumn{1}{l}{ Tecta } & \multicolumn{9}{l}{ Percentage cell type } \\
\cline { 2 - 8 } SD & SS & SSC & LG & SG & ML & RC \\
\hline Normal & 27 & 10 & 2 & 10 & 27 & 8 & 15 \\
& $(14)$ & $(5)$ & $(1)$ & $(5)$ & $(14)$ & $(4)$ & $(8)$ \\
Striped & 44 & 4 & 10 & 7 & 16 & 13 & 4 \\
& $(20)$ & $(2)$ & $(5)$ & $(3)$ & $(7)$ & $(6)$ & $(2)$
\end{tabular}

The number and percent of cells of various categories encountered in normal and striped tecta. Numbers in parentheses are the actual number of each type. SD, small, deep cells; SS, small, superficial cells; SSC, small, superficial, clumped cells; LG, large ganglionic cells; SG, small ganglionic cells; ML, medial-laterally oriented cells; RC, rostral-caudally biased cells. staining in this region of the basal forebrain obscures fine microscopic detail and makes it difficult to resolve individual axons.

Diencephalon. Striking differences are noted in the effects of MDA (or MDMA) upon the thalamus versus the hypothalamus, although individual nuclei were not analyzed systematically. The thalamus, which normally receives a moderate 5-HT innervation, is almost totally denervated of 5-HT axons following treatment with either drug. However, dense accumulations of 5-HT axons remain in a small dorsal, midline zone, the paraventricular nucleus of the thalamus and in the medial habenular nucleus. In contrast, at very low magnification, 5-HT staining of the hypothalamus appears to be generally spared. However, inspection at higher magnification reveals that fine axon terminals are largely ablated after MDA and somewhat less so after MDMA. The medial hypothalamus (especially the dorsomedial and ventromedial nuclei) and the anterior hypothalamic area are largely denervated of 5-HT axon terminals and exhibit a low density of residual fibers. In the lateral hypothalamus, a large number of deeply stained, longitudinally oriented axons remain after drug treatment (Fig. 9). Many of these fibers form part of the MFB and are more intensely stained than in controls. Consequently, the lateral hypothalamus appears to have a greater intensity of 5-HT-immunoreactive staining in treated animals than in controls. The dense staining in this region obscures fine details and will make it necessary to obtain thinner sections for more detailed morphologic analysis. The present results suggest that there is a more severe denervation of the medial than of the lateral hypothalamus; however, spared fibers in the lateral hypothalamus may be primarily axons passing through this region.

\section{Raphe cell bodies}

Following MDA and MDMA treatment, the cell bodies in the dorsal raphe (DR), median raphe (MR) and the B9 cell group are indistinguishable from those in control brains. The raphe cells exhibit normal immunocytochemical staining intensity for 5-HT, and the morphology of cell bodies and dendrites appears unremarkable. In Nissl preparations the morphology of raphe cell bodies in drug-treated rats does not differ from that in 


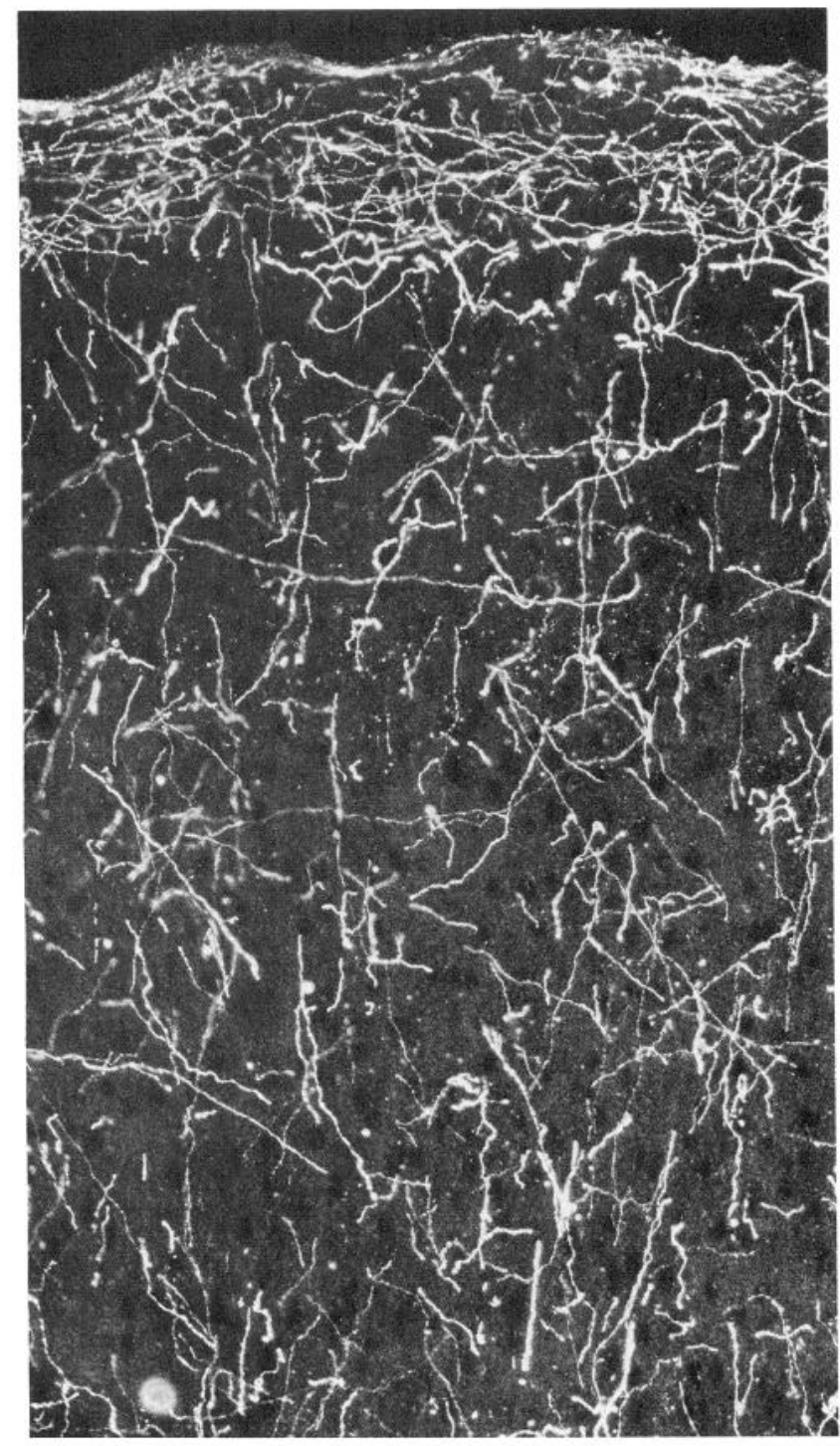

CONTROL

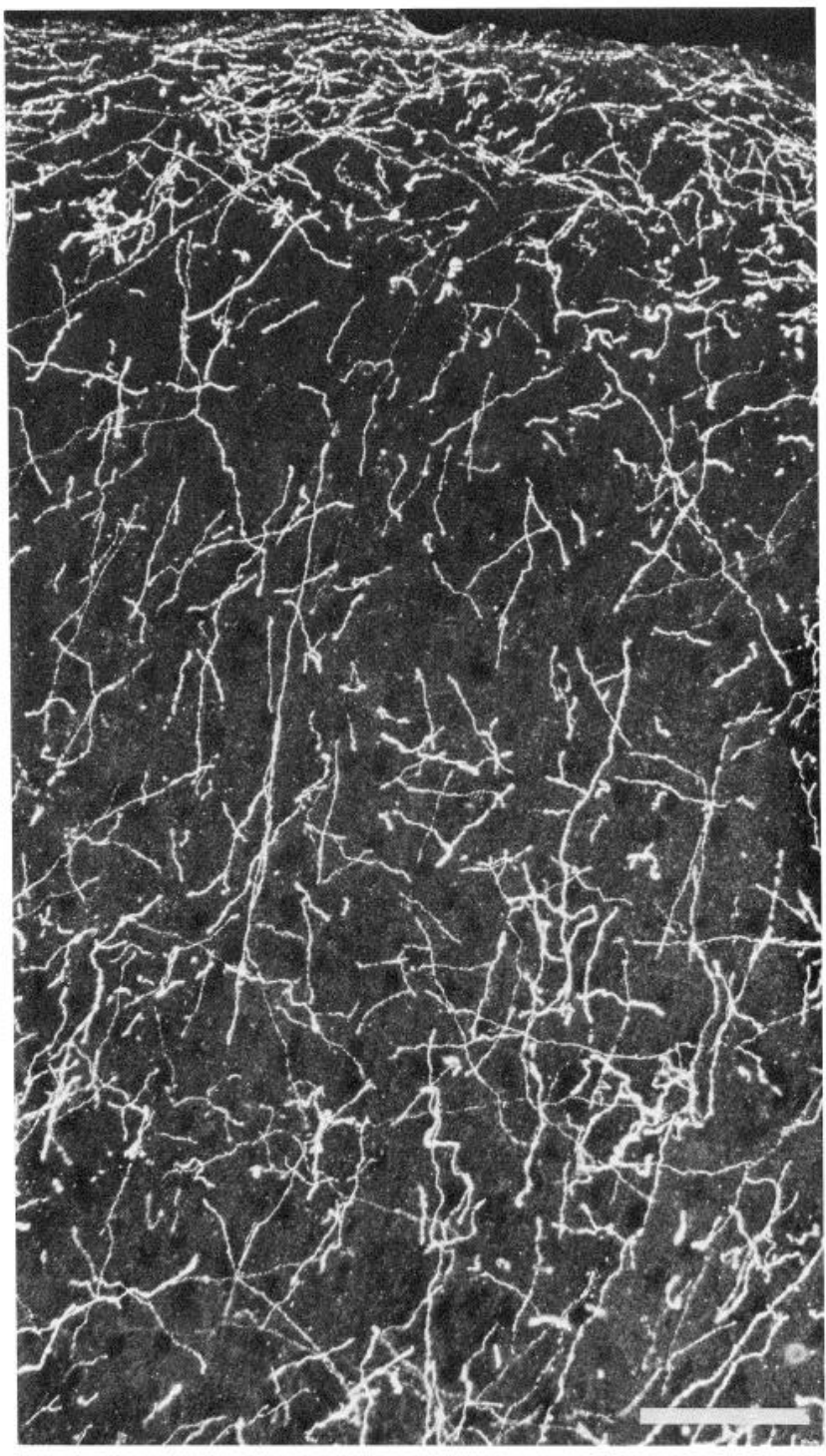

M D A

Figure 10. Catecholamine-containing axons in frontal cortex. These immunocytochemical preparations use an antibody to tyrosine hydroxylase (TH) and therefore stain catecholaminergic axons. This method does not differentiate between dopamine- and norepinephrine-containing axons since both contain TH. There is no detectable change in density or morphology of catecholamine axons following MDA (or MDMA). Two weeks survival. Scale bar, $100 \mu \mathrm{m}$.

controls. The cell bodies in the DR, MR, and B9 groups exhibit normal shape and size and show no evidence of increased staining nor any loss of cytoplasmic Nissl substance that would reflect chromatolysis. Moreover, inspection of Nissl-stained sections throughout the rest of the brain indicates no evidence of altered morphology that might suggest pyknosis or cellular degeneration. However, frozen sections prepared for immunocytochemistry are minimally fixed and do not provide the finest preservation of cytologic detail. Hence, subtle morphologic changes in raphe cells could be obscured, and thinner sections specifically fixed for optimum cytology should be further analyzed.

\section{Catecholamine neurons}

Evaluation of the effects of MDA and MDMA on catecholamine-containing neurons was made possible by incubating brain sections with antibodies to TH. In MDA- and MDMA-treated rats, TH-positive cell bodies and axons do not differ in density, morphology, distribution, or immunoreactivity from comparable structures seen in control brains. In particular, dopaminecontaining cell bodies in the substantia nigra and periaqueductal gray are indistinguishable from those in control animals.

TH-positive axons were found throughout the cortex and in all cortical layers. Numerous fine, varicose catecholamine axon terminals are interspersed with relatively straight, smooth preterminal fibers. There are no changes in TH-positive axon terminals in frontal, parietal, and occipital cortex in drug-treated brains (Fig. 10). In the forebrain, the greatest density of THpositive terminals is normally found in the striatum and the olfactory tubercle. The density of TH-positive axons in these regions is equally high in treated and in control brains. In no regions could the $\mathrm{TH}$ staining in drug-treated brains be distinguished from that in control brains. No decrease in the density 
of catecholamine fibers was detected, and there was no evidence of axon degeneration at short or long survival times.

\section{Discussion}

The present results demonstrate that, following systemic administration, MDA and MDMA cause extensive loss of 5-HT axons in cerebral cortex, striatum, and thalamus. The presence of markedly dilated 5-HT-containing processes and fragmented axon segments at short survival times is evidence of structural damage to 5-HT axons; the subsequent disappearance of most 5-HT axon terminals indicates that these structures degenerate. The terminal portions of 5-HT axons are selectively vulnerable to the neurotoxic effects of MDA and MDMA, whereas preterminal axons, fibers of passage, and raphe cell bodies are not damaged. Regional differences in neurotoxicity are manifested by a greater loss of 5-HT axons in several forebrain areas, particularly neocortex, striatum, and thalamus, while more fibers are spared in hypothalamus, hippocampus, and brain stem.

\section{Degeneration of 5-HT axons}

MDA and MDMA were previously postulated to cause degeneration of 5-HT axons based on biochemical evidence for depletion of 5-HT (Ricaurte et al., 1985; Schmidt et al., 1986; Stone et al., 1986). Studies using the Fink-Heimer method obtained evidence suggestive of MDA- or MDMA-induced degeneration in the striatum (Ricaurte et al., 1985; Commins et al., 1987). However, because of low sensitivity for 5-HT axons, the silverstaining methods do not accurately depict the full extent or regional distribution of degenerating 5-HT axons. A central goal of the present study was to obtain anatomic evidence that would establish whether 5-HT neurons degenerate following exposure to these drugs. The visualization of swollen, fragmented nerve fibers by immunocytochemistry provides direct evidence that 5-HT axons are structurally damaged by exposure to MDA or MDMA. The morphologic criteria used for axon degeneration are based on histofluorescence studies of damaged monoamine axons that were damaged by other neurotoxins (Baumgarten et al., 1973; Bjorklund et al., 1973; Wiklund and Bjorklund, 1980; Jonsson and Nwanze, 1982).

This immunocytochemical study reveals 2 phases of the neurotoxicity. Positive evidence for acute axonal degeneration is detected at short survival times; at longer times after drug administration, the loss of axons reflects lasting denervation. A limitation of transmitter immunocytochemistry for the study of neurotoxicity is that visualization of nerve fibers depends upon the presence of endogenous neurotransmitter. However, MDA and MDMA are known to release 5-HT from nerve terminals in vitro (Nichols et al., 1982) and to reduce levels of 5-HT in the brain (Ricaurte et al., 1985; Schmidt et al., 1986; Commins et al., 1987). While axons that are depleted of 5-HT cannot be detected, the present results show that, 1-3 d after drug administration, sufficient amounts of 5-HT remain to allow visualization of some degenerating terminals. Although evidence for degeneration is clearly seen, due to transmitter depletion, this method may underestimate the number of axons that are degenerating. Transmitter levels stabilize at longer survival times (Schmidt et al., 1986) when the decrease in stained axons accurately indicates the extent of denervation. The loss of most 5-HT axons in cerebral cortex, striatum, and thalamus following administration of MDA shows that this drug is extremely neurotoxic and, in the doses used, produces a lasting and nearly total destruction of the 5-HT innervation of forebrain. MDMA produces an identical pattern of denervation, but the sparing of some fine axons indicates that this $\mathrm{N}$-methylated derivative is a slightly less potent neurotoxin than MDA at the same dose. The similarity in the effects of these drugs in terms of target structures and regional distribution suggests that both drugs have the same mechanism and site of action.

\section{Selective vulnerability of axon terminals}

The use of transmitter immunocytochemistry makes it feasible to identify specific neuron types and subcellular compartments that are damaged by neurotoxic drugs. At long survival times after drug administration ( 2 weeks), the disappearance of fine, arborized 5-HT axons with sparing of smooth, straight preterminal fibers is evidence for selective vulnerability of 5-HT axon terminals. The intense immunoreactivity in dilated axons of passage is presumably caused by the damming-up of neurotransmitter and other axonal constituents secondary to destruction of axon terminals. Similar morphologic changes have been documented previously in monoamine fibers that were experimentally axotomized by selective neurotoxins (Baumgarten et al., 1973; Bjorklund et al., 1973). The presence of 5-HT and other cytoplasmic contents in preterminal axons, fibers of passage, and raphe cell bodies indicates that these cellular compartments remain functionally intact and that transmitter synthesis and axonal transport are not substantially impaired. The morphologic evidence that axon terminals are selectively damaged by MDA and MDMA is in agreement with results demonstrating a large reduction in 5-HT uptake sites (Battaglia et al., 1987). These parallel anatomic and biochemical findings provide evidence that the 5-HT uptake site is preferentially located on axon terminals and may be used as a marker for terminal degeneration.

That the 5-HT uptake receptor may be a principal site at which MDA and MDMA act is suggested by the selective neurotoxicity for axon terminals and by in vitro studies showing that both drugs exhibit high-affinity binding (1-2 $\mu \mathrm{M})$ to $5-\mathrm{HT}$ uptake sites (Battaglia et al., 1986) and inhibit 5-HT uptake into synaptosomes (Nichols, 1986). A role of the presynaptic uptake carrier in the action of these drugs is supported by the demonstration that neurotoxicity can be prevented by $5-\mathrm{HT}$ uptake inhibitors such as fluoxetine or citalopram (Berger et al., 1987; Schmidt, 1987; Battaglia et al., 1988). While not yet demonstrated, the uptake pump may concentrate these drugs within axon terminals, where they could form neurotoxic metabolites, as is postulated for 6-hydroxydopamine (Kostrzewa and Jacobowitz, 1974; Jonsson, 1983). We propose elsewhere that a peripheral (hepatic) metabolite of these drugs may be the actual neurotoxic compound since direct administration of MDA or MDMA into cerebral cortex does not produce loss of 5-HT axons (Molliver et al., 1986).

While most fine 5-HT axon terminals in neocortex are destroyed by MDA or MDMA at the doses used in this study, a small population of coarse, terminal-like axons that have large round varicosities were found to persist. Therefore, fine axon terminals may be especially vulnerable to these neurotoxic drugs, while axons with large varicosities appear to be more resistant to degeneration. Although we have not ruled out the possibility that the large varicosities on spared axons may be pathologic changes, similar 5-HT axons with large varicosities are normally present in cerebral cortex. Beaded axons of this type were recently shown to arise from the median raphe nucleus, while fine axon terminals originate primarily in the dorsal raphe nucleus 
(Kosofsky and Molliver, 1987). Further anatomic studies are being conducted to verify whether there are 2 distinct types of 5-HT axons with differential vulnerability to these drugs and to determine whether they arise from different raphe nuclei.

\section{Regional differences in neurotoxicity}

The morphologic results demonstrate regional differences in vulnerability of serotonergic axons to the neurotoxic effects of MDA and MDMA. Although axon density has not been measured quantitatively, the sparing of 5-HT axons in neocortex (greatest in frontal cortex, least in occipital) appears roughly proportional to the normal innervation density for cach arca. While the drugs produce a uniform degree of denervation in different areas of neocortex, in other areas of forebrain the magnitude of denervation does not follow this simple proportionality. For example, the hippocampus, hypothalamus, and basal forebrain are less depleted of 5-HT axons following MDA or MDMA than are neocortex, striatum, and thalamus.

Several factors appear to underlie the regional differences in neurotoxicity of MDA and MDMA. (1) The greatest loss of 5-HT innervation is in forebrain areas such as neocortex and striatum that contain a dense plexus of highly arborized, fine axon terminals that are especially vulnerable to neurotoxic drug effects. (2) Preterminal axons are resistant to the neurotoxic effects of MDA. The intense 5-HT immunoreactivity in basal forebrain and lateral hypothalamus after drug treatment is located in dilated axons of passage. (3) Regional differences may reflect differential vulnerability of particular axon types. While fine axon terminals degenerate, 5-HT axons with large varicosities appear responsible for residual 5-HT innervation. The regional differences in drug action should be taken into account in attempts to explain the behavioral effects of MDA and MDMA.

The regional anatomic differences in denervation parallel the biochemical changes in 5-HT markers that were obtained following an identical drug regimen (Yeh et al., 1986; Battaglia et al., 1987). The moderate loss of 5-HT axons in hippocampus and hypothalamus matches the relatively small decrease in 5-HT levels reported in these areas (Battaglia et al., 1987). The greater decrease in 5-HT uptake sites found in the same areas corresponds to the marked loss of fine axon terminals that have closely spaced varicosities. Surviving 5-HT fibers are either dilated preterminal axons or coarse axons with large, widely spaced varicosities. Both types of spared fibers exhibit intense immunoreactivity and are likely to have high 5-HT levels but relatively few uptake sites; their presence may account for the partial preservation of 5-HT levels in the hippocampus and hypothalamus.

Our morphologic results indicate that the medial hypothalamus is substantially denervated of 5-HT by MDA and MDMA, while the lateral hypothalamus remains intensely immunoreactive. This differential effect on the medial versus lateral hypothalamus is of particular interest in view of the anorexigenic effects of MDMA (Downing, 1986; Greer and Tolbert, 1986). The demonstration that the ventromedial hypothalamic nucleus is largely denervated of 5-HT axon terminals leads to the suggestion that MDMA and related compounds may influence 5-HT neurotransmission in this nucleus, which may be the site where the anorexic effect of amphetamine derivatives is mediated.

In the striatum, there is an apparent disparity between the profound loss of 5-HT axons in striatal gray matter and the relatively small decrease in 5-HT levels (Ricaurte et al., 1985;
Yeh et al., 1986; Battaglia et al., 1987). It is likely that slices prepared for biochemical assays may have included substriatal tissue from the basal forebrain; the numerous 5-HT axons of passage in this region would greatly increase neurotransmitter levels and indicate erroneously high values for striatal $5-\mathrm{HT}$. The greater reduction in 5-HT uptake sites after MDA (Battaglia et al., 1987) more closely parallels the denervation observed by immunocytochemistry. In support of this view, one recent study (Stone et al., 1986) reports a large reduction in striatal 5-HT markers, consistent with the present results.

\section{Catecholamine innervation is spared}

Immunocytochemical staining for TH demonstrates that catecholamine-containing axons are not damaged by MDA or MDMA. Therefore, although other neurotransmitters have not been studied, the neurotoxic effect of these drugs appears selective for 5-HT axons. This conclusion agrees with biochemical studies that show no decrease in markers for dopamine or norepinephrine (Ricaurte et al., 1985; Stone et al., 1986; Battaglia et al., 1987; Schmidt, 1987). Damage to cortical neurons after much higher doses of MDMA (Commins et al., 1987) may be secondary to cardiovascular effects of amphetamine overdosage (Nichols et al., 1975), which cause cerebral ischemia and hypertension. The ncurotoxicity of MDA and MDMA is more selective than that of methamphetamine, which at high doses damages both catecholamine and 5-HT axons (Seiden et al., 1975; Wagner et al., 1979; Ricaurte et al., 1982). The neurotoxin p-chloroamphetamine also selectively damages 5-HT axons (Sanders-Bush et al., 1972, 1975; Fuller et al., 1975; Mullen et al., 1987) and may have an action similar to MDA.

\section{Possible neurotoxicity in humans}

These results showing that MDA and MDMA produce degeneration of 5-HT axon terminals in rat raise the question of whether these compounds have neuroloxic effects in humans. Considerable caution should be exercised before the results are extrapolated to man, however. The doses employed in this study were selected because of their previously demonstrated ability to lower brain 5-HT levels in the rat (Ricaurte et al., 1985) and are approximately 5-10 times greater than the doses typically used in humans for therapeutic or recreational purposes (Braun et al., 1980; Greer and Tolbert, 1986). Significant reductions in 5-HT uptake sites have since been demonstrated following smaller and fewer doses of MDMA (Battaglia et al., 1988). Moreover, since the metabolism of amphetamines varies in different species (Caldwell, 1976), studies of this type are needed in primates before conclusions can be drawn about the potential hazards of these compounds in humans.

The present study shows that MDA and MDMA cause massive loss of 5-HT innervation in the forebrain and that immunocytochemistry provides a sensitive method for the detection of damaged and degenerating axons. Since this method visualizes the cellular compartment that is affected, drug-induced structural damage to neurons may be of help in identifying the site of action of psychotomimetic drugs. The restricted action of these potent mood-altering drugs at 5-HT axon terminals provides support for the idea that 5 -HT projections play a role in the regulation of affective state. Because of the selective neurotoxicity of MDA and MDMA, these drugs should serve as useful experimental tools for studying the anatomic organization and function of 5-HT projections to the forebrain. 
Note added in proof: Since this paper was accepted for publication several findings highly relevant to the discussion have been obtained and are in press in other journals. MDMA has been found to be considerably more neurotoxic to serotonin axons in the primate brain than in the rat (Ricaurte et al., 1988). Therefore, the use of this drug in humans should be approached with great caution. The regional pattern of degeneration and the differential toxicity of MDMA upon fine 5-HT axons have also been found in the monkey as in the rat (Wilson et al., 1988). Finally, the differential origin of 5-HT axons that are sensitive or resistant to psychotropic amphetamines has been confirmed by means of retrograde axonal transport in a study showing that dorsal raphe axons are selectively vulnerable to the effects of para-chloroamphetamine (Mamounas and Molliver, 1988).

\section{References}

Aghajanian, G. K., W. E. Foote, and M. H. Sheard (1968) Lysergic acid diethylamide: Sensitive neuronal units in the midbrain raphe. Science 161: 706-708.

Aghajanian, G. K., W. E. Foote, and M. H. Sheard (1970) Action of psychotogenic drugs on single midbrain raphe neurons. J. Pharmacol. Exp. Ther. 171: 178-187.

Anderson, G. M., G. Braun, U. Braun, D. E. Nichols, and A. T. Shulgin (1978) Absolute configuration and psychotomimetic activity. Natl. Inst. Drug Abuse Res. Monogr. Ser. 22: 8-15.

Battaglia, G., M. J. Kuhar, and E. B. De Souza (1986) MDA and MDMA (ecstasy) interactions with brain serotonin receptors and uptake sites: In vitro studies. Soc. Neurosci. Abstr. 12: 1234.

Battaglia, G., S. Y. Yeh, E. O'Hearn, M. E. Molliver, M. J. Kuhar, and E. B. De Souza (1987) 3,4-Methylenedioxymethamphetamine (MDMA) and 3,4-methylenedioxyamphetamine (MDA) preferentially destroy serotonin terminals in rat brain: Quantification of neurodegeneration by measurement of ${ }^{3} \mathrm{H}$-paroxetine-labeled serotonin uptake sites. J. Pharmacol. Exp. Ther. 242: 911-916.

Battaglia, Gr., S. Y. Yeh, and F. B. De Souza (1988) MDMA-induced neurotoxicity: Parameters of degeneration and recovery of brain serotonin neurons. Pharmacol. Biochem. Behav. 29: 269-274.

Baumgarten, H. G., A. Bjorklund, L. Lachenmayer, and $\Lambda$. Nobin (1973) Evaluation of the effects of 5,7-dihydroxytryptamine on serotonin and catecholamine neurons in the rat CNS. Acta Physiol. Scand. Suppl. 391: 1-19.

Berger, U., G. Hung, M. E. Molliver, and R. Grzanna (1987) Psychotropic amphetamines have different sites of action at serotonergic (5HT) synapses: A comparison of p-chloroamphetamine (PCA) and 3,4-methlenedioxyamphetamine (MDA) with 2,5-dimethoxy-4methylamphetamine (DOM). Soc. Neurosci. Abstr. 13: 906.

Bjorklund, A., A. Nobin, and U. Stenevi (1973) The use of neurotoxic dihydroxytryptamines as tools for morphological studies and localized lesioning of central indolamine neurons. 7. 7ellforsch. 145:479501.

Braun, U., A. T. Shulgin, and G. Braun (1980) [Research on the central activity and analgesia of $\mathrm{N}$-substituted analogs of the amphetamine derivative 3,4-methylenedioxyphenylisopropylamine.] Arzneimittelforsch. 30: $825-830$.

Caldwell, J. (1976) The metabolism of amphetamines in mammals. Drug Metabol. Rev. 5: 219-280.

Commins, D. L., G. Vosmer, R. M. Virus, W. L. Woolverton, C. R. Schuster, and L. S. Seiden (1987) Biochemical and histological evidence that methylenedioxymethamphetamine (MDMA) is toxic to neurons in the rat brain. J. Pharmacol. Exp. Ther. 241: 338-345.

Commissaris, R. L., W. H. Lyness, K. E. Moore, and R. H. Rech (1980) Enhancement of the behavioral effects of 2,5-dimethoxy-4-methylamphetamine (DOM) by pretreatment with p-chlorophenylalanine. Pharmacol. Biochem. Behav. 13: 605-608.

Di Leo, F. B. (1981) Psychotherapy with psychedelic drugs: A case report. J. Psychoactive Drugs 13: 319-324.

Downing, J. (1986) The psychological and physiological effects of MDMA on normal volunteers. J. Psychoactive Drugs 18: 335-340.
Freedman, D. X. (1961) Effects of LSD-25 on brain serotonin. J. Pharmacol. Exp. Ther. 134; 160-166.

Fuller, R. W., K. W. Perry, and B. B. Molloy (1975) Reversible and irreversible phases of serotonin depletion by 4-chloroamphetamine. Eur. J. Pharmacol. 33: 119-124.

Gerfen, C. R. (1985) The neostriatal mosaic. I. Compartmental organization of projections from the striatum to the substantia nigra in the rat. J. Comp. Neurol. 236: 454-476.

Glennon, R. A. (1985) Involvement of serotonin in the action of hallucinogenic agents. In Neuropharmacology of Serotonin, A. R. Green, ed., pp. 253-280, Oxford U. P., New York.

Glennon, R. A., and R. Young (1984a) MDA: A psychoactive agent with dual stimulus effects. Life Sci. 34: 379-383.

Glennon, R. A., and R. Young (1984b) Further investigation of the discriminative stimulus properties of MDA. Pharmacol. Biochem. Behav. 20: 501-505.

Glennon, R. A., and R. Young (1984c) MDA: An agent that produces stimulus effects similar to those of 3,4-DMA, LSD and cocaine. Eur. J. Pharmacol. 99: 249-250.

Glennon, R. A., R. Young, J. A. Rosecrans, and G. M. Anderson (1982) Discriminative stimulus properties of MDA analogs. B1ol. Psychiatry 17: 807-814.

Glennon, R. A., M. Titeler, and J. D. McKenney (1984) Evidence for $5-\mathrm{H}^{2} 2$ involvement in the mechanism of action of hallucinogenic agents. Life Sci. 35: 2505-2511.

Greer, G., and R. Tolbert (1986) Subjective reports of the effects of MDMA in a clinical setting. J. Psychoactive Drugs 18: 319-327.

Grinspoon, L., and J. B. Bakalar (1986) Can drugs be used to enhance the psychotherapeutic process? Am. J. Psychother. 40: 393-404.

Hedreen, J. C. (1973) A direct projection from tegmentum to cortex and hippocampus demonstrated with the Nauta and Fink-Heimer methods. Anat. Rec. 175: 340

Heym, J., K. Rasmussen, and B. L. Jacobs (1984) Some behavioral effects of hallucinogens are mediated by a postsynaptic serotonergic action: Evidence from single unit studies in freely moving cats. Eur. J. Pharmacol. 101: 57-68.

Hsu, S. M., L. Raine, and H. Fanger (1981) The use of avidin-biotin peroxidase complex $(\mathrm{ABC})$ in immunoperoxidase techniques: $\mathrm{A}$ comparison between $\mathrm{ABC}$ and unlabeled antibody (PAP) procedures. $\mathbf{J}$. Histochem. Cytochem. 29: 577-580.

Jonsson, G. (1983) Chemical lesioning techniques: Monoamine neurotoxins. In Handbook of Chemical Neuroanatomy, Vol. 1: Methods in Chemical Neuroanatomy, A. Bjorklund and T. Hökfelt, eds., pp. 463-507, Elsevier, New York.

Jonsson, G., and E. Nwanze (1982) Selective (+)-amphetamine neurotoxicity on striatal dopaminc nerve terminals in the mouse. $\mathrm{Br} . \mathrm{J}$. Pharmacol. 77: 335-345.

Klein, J. (1985) The new drug they call "Ecstasy." Is it too much to swallow? In New Yorker Magazine, May 20, pp. 38-43.

Kohler, C. (1982) On the serotonergic innervation of the hippocampal region: An analysis employing immunohistochemistry and retrograde fluorescent tracing in the rat brain. In Cytochemical Methods in Neuroanatomy, S. L. Palay and V. Chan-Palay, eds., pp. 387-405, Liss, New York.

Kosofsky, B. E., and M. E. Molliver (1987) The serotoninergic innervation of cerebral cortex: Different classes of axon terminals arise from dorsal and median raphe nuclei. Synapse 1: 335-345.

Kostrzewa, R. M., and D. M. Jacobowitz (1974) Pharmacological actions of 6-hydroxydopamine. Pharmacol. Rev. 26: 199-288.

Lidov, H. G. W., R. Grzanna, and M. E. Molliver (1980) The scrotonin innervation of the cerebral cortex in the rat-An immunohistochemical analysis. Neuroscience 5: 207-227.

Mamounas, L. A., and M. E. Molliver (1988) Evidence for dual serotonergic projections to neocortex: Axons from the dorsal and median raphe nuclei are differentially vulnerable to the neurotoxin p-chloroamphetamine (PCA). Exp. Neurol. (in press).

Marquardt, G. M., V. DiStefano, and L. L. Ling (1978) Pharmacological effects of $+/-, \mathrm{S}$, and R-MDA. In Psychopharmacology of Hallucinogens, R. Stillman and R. Willette, eds., pp. 84-104, Pergamon, New York.

Molliver, M. E., E. O'Hearn, G. Battaglia, and E. B. De Souza (1986) Direct intracerebral administration of MDA and MDMA does not produce serotonin neurotoxicity. Soc. Neurosci. Abstr. 12: 1234.

Moore, R. Y., and A. Hellcr (1967) Monoaminc levels and neuronal degeneration in rat brain following lateral hypothalamic lesions. $\mathrm{J}$. Pharmacol. Exp. Ther. 156: 12-22. 
Mullen, C., L. A. Mamounas, E. O'Hearn, and M. E. Molliver (1987) Dual serotonergic projections to forebrain in the rat: I wo classes of axon terminals exhibit differ sntial vulnerability to the psychotropic drugs p-chloroamphetamine (PCA) and 3,4-methylenedioxyamphetamine (MDA). Soc. Neurosci. Abstr. 13: 907.

Naranjo, C., A. T. Shulgin, and T. Sargent (1967) Evaluation of 3,4methylenedioxyamphetamine (MDA) as an adjunct to psychotherapy. Med. Pharmacol. Exp. (Basel) 17: 359-364.

Nichols, D. E. (1986) Differences between the mechanism of action of MDMA, MBDB, and the classic hallucinogens. Identification of a new therapeutic class: Entactogens. J. Psychoactive Drugs 18: 305313.

Nichols, D. E., M. Ilhan, and J. P. Long (1975) Comparison of cardiovascular, hyperthermic and toxic effects of para-methoxyamphetamine (PMA) and 3,4-methylenedioxyamphetamine (MDA). Arch. Int. Pharmacodyn. Ther. 214: 133-140.

Nichols, D. E., D. H. Lloyd, A. J. Hoffman, M. B. Nichols, and G. K. Yim (1982) Effects of certain hallucinogenic amphetamine analogues on the release of $\left[{ }^{3} \mathrm{H}\right]$ serotonin from rat brain synaptosomes. J. Med. Chem. 25: 530-535.

Nozaki, M., D. B. Vaupel, and W. R. Martin (1977) A pharmacologic comparison of 3,4-methylenedioxyamphetamine and LSD in the chronic spinal dog. Eur. J. Pharmacol. 46: 339-349.

Ricaurte, G. A., R. W. Guillery, L. S. Seiden, C. R. Schuster, and R. Y. Moore (1982) Dopamine nerve terminal degeneration produced by high doses of methylamphetamine in the rat brain. Brain Res. 235: 93-103.

Ricaurte, G. A., G. Bryan, L. Strauss, L. Seiden, and C. Schuster (1985) Hallucinogenic amphetamine selectively destroys brain serotonin nerve terminals. Science 229: 986-988.

Ricaurte, G. A., L. S. Forno, M. A. Wilson, L. E. Delanney, I. Irwin, M. E. Molliver, and J. W. Langston (1988) ( \pm )3,4-methylenedioxymethamphetanine (MDMA) selectively damages central serotonergic neurons in non-human primates. J. Am. Med. Assoc. 260:5155.

Sanders-Bush, E., J. A. Bushing, and F. Sulser (1972) Long-term effects of p-chloroamphetamine on tryptophan hydroxylase activity and on levels of 5-hydroxytryptamine and 5-hydroxyindole acetic acid in brain. Eur. J. Pharmacol. 20: 385-388.

Sanders-Bush, E., J. A. Bushing, and F. Sulser (1975) Long-term effects of p-chloroamphetamine and related drugs on central serotonergic mechanisms. J. Pharmacol. Exp. Ther. 192: 33-41.

Schmidt, C. J. (1987) Neurotoxicity of the psychedelic amphetamine methylenedioxymethamphetamine. J. Pharmacol. Exp. Ther. 240. $1-7$.

Schmidt, C. J., L. Wu, and W. Lovenberg (1986) Methylenedioxymethamphetamine: A potentially neurotoxic amphetamine analogue. Eur. J. Pharmacol. 124: 175-178.

Seiden, L. S., M. W. Fischman, and C. R. Schuster (1975) Long-term methamphetamine-induced changes in brain catecholamines in tolerant rhesus monkeys. Drug Alcohol Depend. 1: 215-219.

Seymour, R. B. (1986) MDMA, Haight-Ashbury Publications, San Francisco.

Shannon, M., G. Battaglia, R. A. Glennon, and M. Titeler (1984) 5-HT1 and 5-HT2 binding properties of derivatives of the hallucinogen 1-(2,5-dimethoxyphenyl)-2-aminopropane (2,5-DMA). Eur. I. Pharmacol. 102: 23-29.

Shulgin, A. T. (1978) Psychotomimetic drugs: Structure-activity relationships. In Handbook of Psychopharmacology, Vol. 11, L. L. Iversen, S. D. Iversen, and S. H. Snyder, eds., pp. 243-333, Plenum, New York.

Shulgin, A. T., and D. E. Nichols (1976) Characterization of three new psychotomimetics. In The Psychopharmacology of Hallucinogens, R. Stillman and R. Willette, eds., pp. 74-83, Pergamon, New York.

Siegel, R. K. (1986) MDMA-Nonmedical use and intoxication. J. Psychoactive Drugs 18: 349-354.

Steinbusch, H. W. M., A. A. J. Verhofstad, and H. W. J. Joosten (1978) Localization of serotonin in the central nervous system by immunohistochemistry: Description of a specific and sensitive technique and some applications. Neuroscience 3: 811-819.

Stone, D. M., D. C. Stahl, G. R. Hanson, and J. W. Gibb (1986) The effects of 3,4-methylenedioxymethamphetamine (MDMA) and 3,4 methylenedioxyamphetamine (MDA) on monoaminergic systems in the rat brain. Eur. J. Pharmacol. 128: 41-48.

Thiessen, P. N., and D. A. Cook (1973) The properties of 3,4-methylenedioxyamphetamine (MDA). I. A review of the literature. Clin. Toxicol. 6: 45-52.

Wagner, G. C., L. S. Seiden, and C. R. Schuster (1979) Methamphetamine induced changes in brain catecholamines in rats and guinea pigs. Drug Alcohol Depend. 4: 435-438.

Wiklund, L., and A. Bjorklund (1980) Mechanisms of regrowth in the bulbospinal serotonin system following 5,6-dihydroxytryptamine induced axotomy. II. Fluorescence histochemical observations. Brain Res. 191: 129-160.

Wilson, M. A., G. A. Ricaurte, and M. E. Molliver (1988) Distinct morphologic classes of serotonergic axons in primates exhibit differential vulnerability to the psychotrophic drug 3,4-methylenedioxymethamphetamine. Neuroscience (in press).

Yeh, S. Y., G. Battaglia, E. O'Hearn, M. E. Molliver, M. J. Kuhar, and E. B. De Souza (1986) Effects of MDA and MDMA (Ecstasy) on brain monoaminergic systems: In vivo studies. Soc. Neurosci. Abstr. 12: 1234

Yensen, R., F. B. Di Leo, J. C. Rhead, W. A. Richards, R. A. Soskin, B. Turek, and A. A. Kurland (1976) MDA-assisted psychotherapy with neurotic outpatients: A pilot study. J. Nerv. Ment. Dis. 163: 233-245. 